\title{
Complex transcriptional circuitry at the G1/S transition in Saccharomyces cerevisiae
}

\author{
Christine E. Horak, ${ }^{1}$ Nicholas M. Luscombe, ${ }^{2}$ Jiang Qian, ${ }^{2}$ Paul Bertone, ${ }^{1}$ Stacy Piccirrillo, ${ }^{1}$ \\ Mark Gerstein, ${ }^{2}$ and Michael Snyder ${ }^{1,3}$ \\ ${ }^{1}$ Department of Molecular, Cellular, and Developmental Biology and ${ }^{2}$ Department of Molecular Biophysics \\ and Biochemistry, Yale University, New Haven, Connecticut 06520-8103, USA
}

In the yeast Saccharomyces cerevisiae, SBF ( $\underline{S} w i 4-S w i 6$ cell cycle box binding factor) and MBF (MluI binding factor) are the major transcription factors regulating the START of the cell cycle, a time just before DNA replication, bud growth initiation, and spindle pole body (SPB) duplication. These two factors bind to the promoters of 235 genes, but bind less than a quarter of the promoters upstream of genes with peak transcript levels at the G1 phase of the cell cycle. Several functional categories, which are known to be crucial for G1/S events, such as SPB duplication/migration and DNA synthesis, are under-represented in the list of SBF and MBF gene targets. SBF binds the promoters of several other transcription factors, including HCM1, PLM2, POG1, TOS4, TOS8, TYE7, YAP5, YHP1, and YOX1. Here, we demonstrate that these factors are targets of SBF using an independent assay. To further elucidate the transcriptional circuitry that regulates the G1-to-S-phase progression, these factors were epitope-tagged and their binding targets were identified by chIp-chip analysis. These factors bind the promoters of genes with roles in G1/S events including DNA replication, bud growth, and spindle pole complex formation, as well as the general activities of mitochondrial function, transcription, and protein synthesis. Although functional overlap exists between these factors and MBF and SBF, each of these factors has distinct functional roles. Most of these factors bind the promoters of other transcription factors known to be cell cycle regulated or known to be important for cell cycle progression and differentiation processes indicating that a complex network of transcription factors coordinates the diverse activities that initiate a new cell cycle.

[Keywords: Yeast; transcription; chIp-chip; cell cycle; SBF; MBF]

Supplemental material is available at http://www.genesdev.org.

Received September 9, 2002; revised version accepted October 9, 2002.

Transcriptional gene regulation is a key component of controlling the processes of cellular differentiation and cell division. In the yeast Saccharomyces cerevisiae, the periodic alteration of gene transcript levels is a major driving force of the cell cycle with the expression level of $\sim 12 \%$ of all yeast genes fluctuating throughout the cell cycle (Cho et al. 1998; Spellman et al. 1998). The functional classes of genes that show periodic transcription mirror the events that are occurring throughout the cell cycle, including DNA synthesis, bud emergence and growth, and SPB duplication and migration. It is, therefore, of central interest to understand how these periodic fluctuations are regulated.

Over half of the genes that exhibit periodic changes in expression peak early in the cell cycle around the G1/S transition (Cho et al. 1998; Spellman et al. 1998). Understanding how these genes are controlled is important for

${ }^{3}$ Corresponding author.

EMAIL michael.snyder@yale.edu; FAX (203) 432-6161.

Article and publication are at http://www.genesdev.org/cgi/doi/10.1101/ gad.1039602. elucidating the complex events that occur at START. SBF (Swi4-Swi6 cell cycle box binding factor) and MBF (MluI binding factor) are two transcriptional regulators that act early in the cell cycle (Andrews and Herskowitz 1989a; Breeden and Mikesell 1991; Koch et al. 1993; Dirick et al. 1995). SBF and MBF are both heterodimeric and share the regulatory subunit, Swi6. However, SBF is composed of the DNA-binding component, Swi4, and MBF contains Mbp1, another sequence-specific DNA-associated protein (Andrews and Herskowitz 1989a,b; Moll et al. 1992; Primig et al. 1992). Together SBF and MBF bind a total of 235 gene promoters, including those upstream of the G1- and S-phase cyclin genes (Iyer et al. 2001). Surprisingly, SBF and MBF combined bind only $23 \%$ of the promoters adjacent to genes with a peak transcript level at G1 and $12 \%$ of promoters that neighbor genes with peak transcript levels in the DNA synthesis phase of the cell cycle.

SBF and MBF primarily target genes with functions that are important for the processes of bud growth and DNA synthesis, initial events of the cell cycle /Verma et 
al. 1992; Igual et al. 1996; Madden et al. 1997; Iyer et al. 2001). However, they target very few genes involved in ubiquitin-dependent proteolysis, another important activity for cell cycle progression through $\mathrm{S}$ phase, and almost no genes involved in formation and migration of the spindle pole complex (Schwob et al. 1994; Barral et al. 1995; Deshaies et al. 1995; Willems et al. 1996; Verma et al. 1997). In addition, not all DNA synthesis genes were shown to be targets of SBF/MBF. Other transcription factors may contribute to these events at the G1/S transition.

Using chromatin immunoprecipitation (chIp) and genomic microarray hybridizations, we found that SBF binds the promoters of several other transcription factors. These include HCM1, which is also a target of MBF, PLM2, POG1, TOS4 (Target of $\underline{\text { SBF}), ~ T O S 8, ~ T Y E 7, ~ Y A P 5, ~}$ $Y H P 1$, and $Y O X 1$. These factors are not essential for cell growth but may play a role in regulating the periodic expression of genes during G1/S and may regulate genes that function in proteolysis, spindle pole duplication, and DNA synthesis, as well as other G1/S-specific activities. Over half of these aforementioned transcription factor genes exhibit peak transcript levels during the late G1 or S phase of the cell cycle, which further implicates them in a role of early cell cycle regulation.

Limited phenotypic and expression data is available for most of these transcription factors. Hcm 1 is a homo$\log$ of Fkh1 and Fkh2, the forkhead transcription factors, known to play an important role during the G2 phase of the cell cycle (Koranda et al. 2000; Kumar et al. 2000; Pic et al. 2000; Zhu et al. 2000; Simon et al. 2001). A mutant of Hcm 1 can suppress the spindle pole defects of a calmodulin mutant, without directly altering its transcript levels (Zhu et al. 1993; Zhu and Davis 1998). Yhp1, Yox1, and Tos 8 are homeodomain-containing transcription factors. Yhpl is presumed to regulate the IME1 gene based on one-hybrid studies; however, IME1 transcript levels are not altered in a yhp1s mutants (Kunoh et al. 2000). Yhp1 shares 38\% identity with Yox1, which has been shown to bind a leucine tRNA gene in vitro (Kaufmann 1993). The transcriptional role of the other homeodomain-containing factor Tos 8 has not been characterized, but TOS 8 expression has been shown by genomic expression profiling to be induced during meiosis and under cell-damaging conditions (Jelinsky et al. 2000; Rabitsch et al. 2001).

The homologs Plm 2 and Tos 4 are also binding targets of SBF. They have no known DNA-binding motif, but they are predicted to be chromatin-associated (Kumar et al. 2002). PLM2 is induced at START and upon exposure to DNA-damaging agents (Spellman et al. 1998; Gasch et al. 2001). TOS4 expression is also induced at START but is repressed by the yeast mating pheromone $\alpha$-factor (Spellman et al. 1998; Breitkreutz et al. 2001). SBF also binds the promoter of POG1. POG1 transcript levels peak during $\mathrm{G} 2 / \mathrm{M}$ and its overexpression blocks a G1 arrest induced by $\alpha$-factor (Leza and Elion 1999). TYE7 encodes for a basic helix-loop-helix factor that, when deleted, incurs sporulation defects. Tye 7 is predicted to regulate expression of glycolytic genes (Nishi et al. 1995;
Sato et al. 1999). The phenotype of YAP5 null mutant has not yet been characterized.

To further understand the events of the G1/S transition, we sought to define the transcriptional targets and functional roles of these transcription factors that are targets of SBF. We first confirmed that these nine factors are bona fide targets of Swi4. We then performed chIpchip analysis on these transcription factors to comprehensively identify their direct binding targets across the yeast genome, and we find that many of them preferentially regulate specific functional classes of genes. In addition, we find that they bind the promoters of many other transcription factor genes. The comprehensive analysis of the gene targets of the nine transcription factors implicated in G1/S control suggests a complex regulatory cascade may control the events surrounding START of the cell cycle.

\section{Results}

Many targets of SBF are transcription factors

Swi4, the DNA-binding component of SBF, was determined to bind upstream of 183 genes by chIp-chip analysis (Iyer et al. 2001). Among these were 14 transcription factor genes, including the SWI4 promoter itself, GAT2, HCM1, NDD1, PDR1, PLM2, POG1, SOK2, TOS4, TOS8, TYE7, YAP5, YHP1, and YOX1. Twelve of these promoters, along with 14 other putative Swi4 targets were tested for Swi4 binding by chromatin immunoprecipitation in combination with PCR assay to verify the microarray results.

For these assays, primers were designed to flank predicted Swi4 binding sites or SCB (̂wi4-Swi6 cell cycle box) elements within 500 bp upstream of the start codon for the putative Swi4 targets (see Supplementary Table 1 for sequences). DNA that was immunoprecipitated from the Swi4-HA tagged strain and an untagged strain was amplified by PCR with these primers. Twenty-two of the 26 promoters tested were enriched in Swi4-HA immunoprecipitates over immunoprecipitated DNA from the untagged strain. The four promoters that did not exhibit enrichment (pCLN3, $\mathrm{p} R A X 2, \mathrm{p} C L A 4$, and $\mathrm{p} C H S 5)$ may still be bona fide Swi4 targets, but Swi4 may bind further than 500 bp upstream within these promoters.

The results for the transcription factor gene promoters are presented in Figure 1. All 12 transcription factor promoters tested show an enrichment, ranging from 1.8-fold to 12.6-fold when Swi4-HA-immunoprecipitated DNA is used as template compared with the control strain (Fig. 1). As expected, the promoter of the CLN2 gene, a G1 cyclin and known target of SBF, is enriched, whereas the negative controls, URA3, SUC2, and MBP1 promoters are not enriched.

ChIp-chip analyses of transcription factors Hcm1, Plm2, Pog1, Tos4, Tos8, Tye7, Yap5, Yhp1, and Yox1 reveals many gene targets

To further elucidate the transcriptional regulatory network that occurs at the G1/S transition, nine transcrip- 


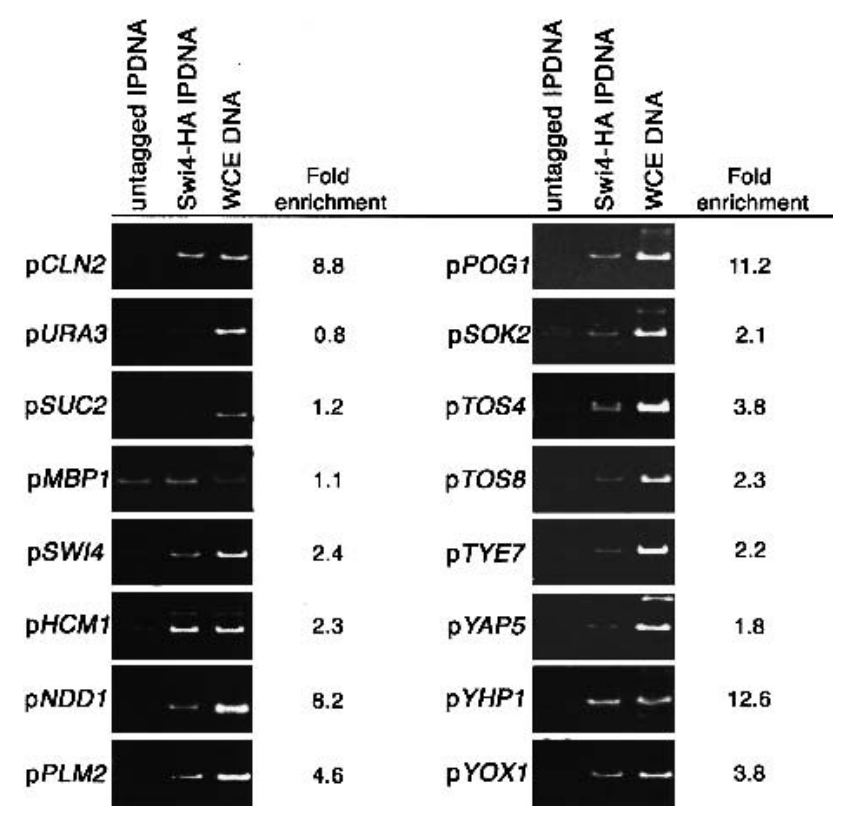

Figure 1. PCR assays of promoters of transcription factor genes identified as Swi4-binding targets by chIp-chip analysis. Primers against the indicated promoter regions were used to amplify DNA immunoprecipitated with HA antibody from either a Swi4-3xHA-tagged strain (lane 2) or untagged strain (lane 1). DNA purified from whole-cell extract was used as a positive control in each assay (lane 3). pURA3 and $\mathrm{p} S U C 2$ are irrelevant promoter sequences that are not expected to be enriched in Swi4-associated chromatin and pCLN2 contains known Swi4binding sequences. Relative enrichments of the amplified products from immunoprecipitates of the tagged strain vs. the untagged control are provided.

tion factor genes that were verified to be SBF targets above were tagged with three copies of the hemagglutinin epitope (3xHA) to enable their analysis by chIp-chip. HCM1, TOS4, TOS8, YAP5, and YHP1 were tagged at the $\mathrm{C}$ terminus by homologous recombination. PLM2, POG1, TYE7, and YOX1 were randomly tagged with the HA epitope by transposon insertion (HAT tag) at amino acid 391, 306, 150, and 7, respectively (Ross-MacDonald et al. 1997). All tagged proteins exhibited wild-type growth rates and morphology. The tagged proteins were immunoprecipitated with an antibody against the hemagglutinin epitope, separated by SDS-PAGE, and visualized by immunoblotting. Figure 2 shows immunoblotting results for five tagged transcription factors with unique molecular weights. Hcm1-3xHA, Plm2-HAT, Tos4-3xHA, Tos8-3xHA, Tye7-HAT, Yap5-3xHA, Yhp1-3xHA, and Yox1-HAT migrate with proteins of molecular weights of approximately $80 \mathrm{kD}, 70 \mathrm{kD}, 70$ $\mathrm{kD}, 40 \mathrm{kD}, 40 \mathrm{kD}, 45 \mathrm{kD}, 45 \mathrm{kD}$, and $45 \mathrm{kD}$, respectively. Proteins of the expected size were observed in all cases, except for Pog1-HAT, which migrated faster than anticipated at around $27 \mathrm{kD}$ rather than the predicted size of $35 \mathrm{kD}$, which perhaps reflects degradation of this protein (Fig. 2).

To identify the genomic targets of each of these factors, DNA associated with the HA-tagged proteins was isolated by chIp from haploid cells growing asynchronously in rich media. This DNA was amplified, labeled, and used to probe a microarray, representing all of the yeast intergenic regions. As a background probe, DNA immunoprecipitated from an untagged strain was used. A median ratio of signal from the labeled immunoprecipitated DNA of the tagged strain (Cy5-labeled) relative to that of the untagged strain (Cy3-labeled) was calculated for each intergenic region from two to five replicate experiments. Figure 3 shows the results for three transcription factors. In these chIp-chip analyses, intergenic regions are considered enriched if their median ratios are at least 3.89 standard deviations $(\mathrm{p}<0.0001)$ from the predicted noise distribution, which is those data points that have a median Cy3 signal greater than that of Cy5 (see Materials and Methods). Negative control experiments were also performed where DNA from an untagged strain was labeled with both fluors and hybridized to the intergenic microarray. Very few deviations from the normal distribution are observed in these experiments (Fig. 3). Complete data sets for all transcription factors in this study can be accessed via the Internet at the Saccharomyces Gene Regulatory Network (http:// array.mbb.yale.edu/yeast/transcription).

Table 1 summarizes the results of these chIp-chip analyses. Each factor bound 30-229 promoter regions (an average of 121 promoters); Yoxl bound the most and Tye 7 the least. Figure 4 shows the relative localization of the binding sites for each of these factors across the genome. For the most part, there is an even distribution of binding sites for each factor. There are some regions, particularly in the repetitive telomeric regions of chromosomes, that are bound by nearly all of the factors, which may be an artifact of the amplification step used in the labeling protocol and/or cross-hybridization. Re-

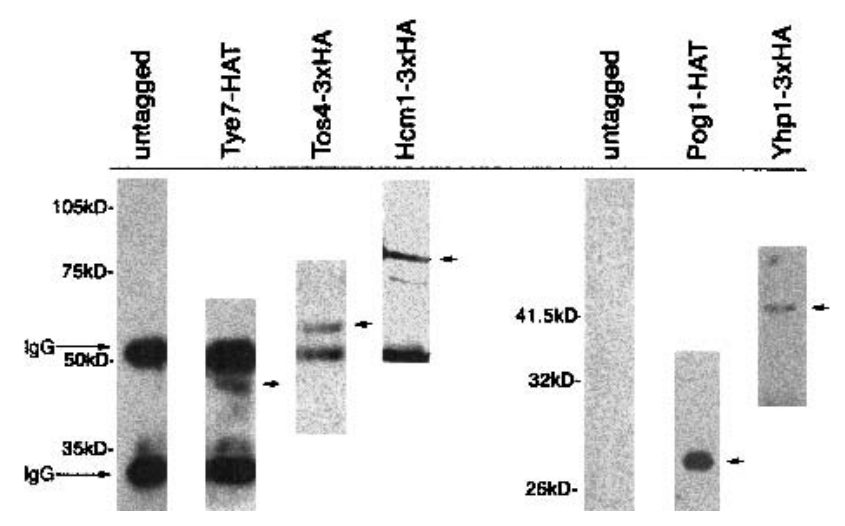

Figure 2. Immunoblots of five epitope-tagged transcription factors are shown. The hemagglutinin tagged proteins were immunoprecipitated with HA antibody 12CA5 (left) or with this antibody directly conjugated to sepharose beads (right) and subsequently separated on a denaturing SDS-PAGE gel and immunoblotted with HA antibody. For each immunoprecipitation method, an immunoblot of an untagged control is provided as a reference. Arrows indicate the appropriate size band for the corresponding tagged protein; approximate molecular weights are given and the IgG bands are indicated. 
Horak et al.

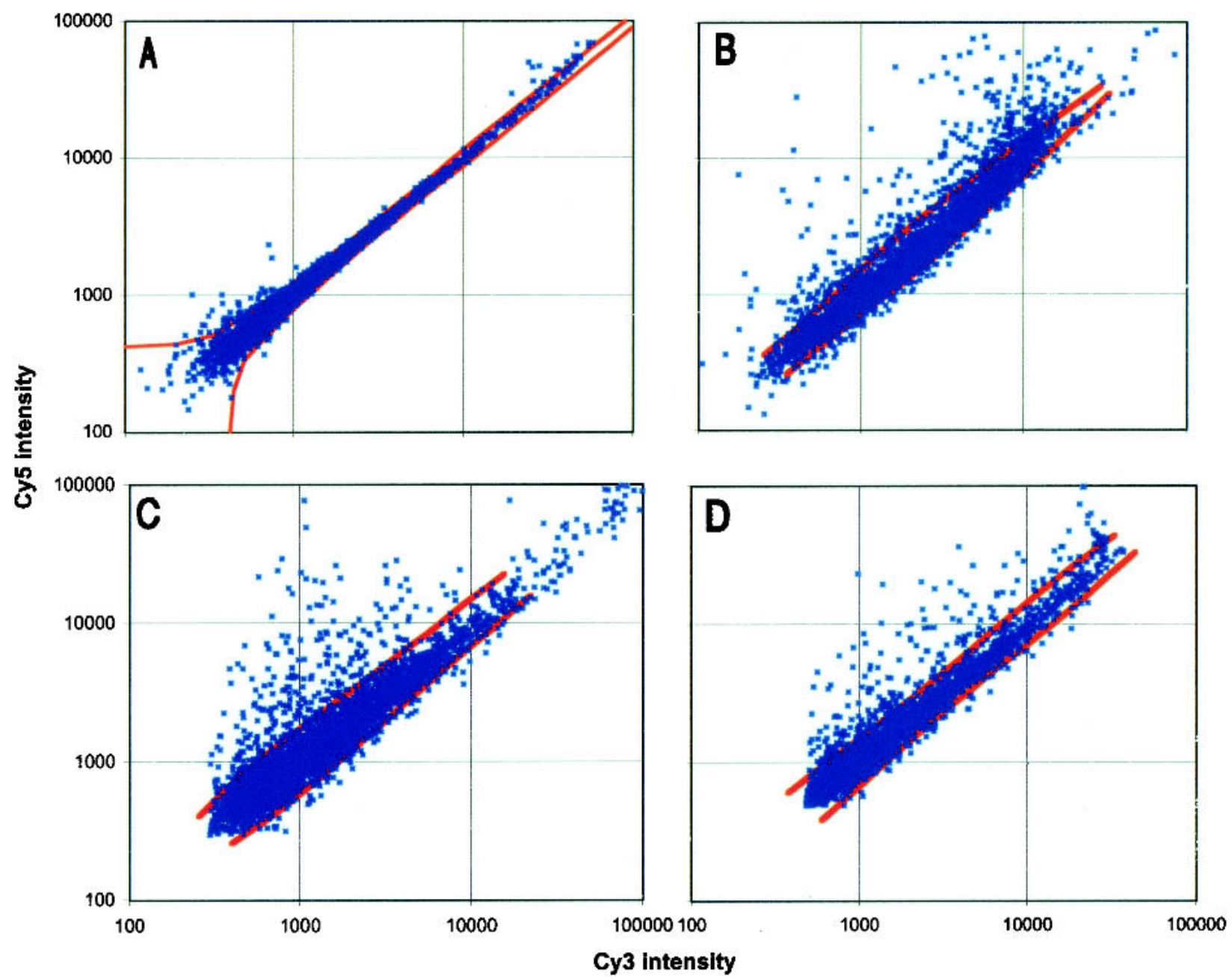

Figure 3. Scatterplots of mean Cy5 and Cy3 intensities of replicate chIp-chip experiments for three transcription factors and the negative control experiment. Each data point represents an individual intergenic region. The median Cy5 signal intensities for each region were plotted against median Cy3 signal intensities from replicate experiments. $(A)$ Scatterplot for the chIp DNA probe from an untagged strain vs. an untagged strain. $(B-D)$ Scatterplots for chIp DNA probe from the HA-tagged strains $(C y 5)$ of $\mathrm{Hcm} 1(B)$, Tos4 $(C)$, and Yhp1 $(D)$ vs. an untagged strain (Cy3).

gions upstream of the nearly 250 tRNA genes are also represented on the microarray. Yox 1 binds $10 \%$ of these regions, including three that neighbor leucine tRNA genes (see Discussion). These intergenic regions are sometimes adjacent to the $5^{\prime}$ end of other genes and are thus targets of the other transcription factors in this study, but they bind a lower proportion of these regions, ranging from $0 \%-3 \%$.

A number of the targets identified for the transcription factors determined by chIp-chip analysis have been verified by PCR assay. These results are shown in Figure 5. Tos8-3xHA immunoprecipitates are enriched for PLM2 and $H O$ promoter sequences. Regions of the POG1 and FKH1 promoter are enriched in Plm2-HAT-associated DNA. The sequences upstream of FHL1 and FKH1 were enriched in Pog1-HAT and Tos4-3xHA immunoprecipitates, respectively. Enrichments for the CLB1 and A1 promoters were also observed in Yhp1-3xHA-immunoprecipitated DNA. These assays also verified enrichment for PHD1 and PLM2 promoter regions in Yox1-HATassociated DNA fragments.

Primers used for these assays were designed to 200$300 \mathrm{bp}$ regions immediately upstream of the "ATG" codon. Several of these interactions appear to be only mild enrichments in the tagged strain immunoprecipitates, ranging from 1.8 to 2.9 ; this may reflect suboptimal primer positions within the sequence $5^{\prime}$ to the putative target gene relative to the transcription factor binding site.

The transcription factors bind to specific functional classes of genes

To help determine the functional role of each transcription factor, the specific MIPS functional category of each binding target was determined. Many of these specific MIPS subcategories were combined to create the follow- 
Table 1. Summary of $G 1 / S$ transcription factors target genes

\begin{tabular}{|c|c|c|c|c|c|}
\hline $\begin{array}{l}\text { Transcription } \\
\text { factor }\end{array}$ & $\begin{array}{l}\text { Number of } \\
\text { promoter } \\
\text { targets }\end{array}$ & $\begin{array}{l}\text { Number of } \\
\text { putative } \\
\text { gene targets }\end{array}$ & Major functional categories & Examples of putative gene targets & $\begin{array}{l}\text { Percentage of } \\
\text { promoters } \\
\text { that neighbor } \\
\text { cell cycle } \\
\text { regulated genes }\end{array}$ \\
\hline Hcm 1 & 192 & 262 & $\begin{array}{l}\text { Cell wall and plasma } \\
\text { membrane synthesis, mitosis } \\
\text { and spindle function }\end{array}$ & CIN8, ASE1, AMS1 & $21 \%$ \\
\hline $\operatorname{Plm} 2$ & 146 & 197 & $\begin{array}{l}\text { DNA synthesis/repair, } \\
\text { chromosome segregation, } \\
\text { nuclear division, } \\
\text { transcription }\end{array}$ & CHK1, CBF1, STU1, POG1 & $15 \%$ \\
\hline Pog1 & 73 & 96 & $\begin{array}{l}\text { Cell cycle regulation, } \\
\text { cytoskeletal function, spindle } \\
\text { assembly }\end{array}$ & GIF1, SLA1, SPC105, BAR1 & $20 \%$ \\
\hline Tos4 & 166 & 230 & $\begin{array}{l}\text { Pheromone response, } \\
\text { transcription }\end{array}$ & FIG2, STE12 & $21 \%$ \\
\hline Tos8 & 181 & 256 & Bud growth & BNI4, BEM3 & $20 \%$ \\
\hline Tye7 & 30 & 38 & $\begin{array}{l}\text { Mitochondrial function, } \\
\text { sporulation }\end{array}$ & YFH1, PEX14, SPO70 & $13 \%$ \\
\hline Yap5 & 106 & 147 & $\begin{array}{l}\text { DNA synthesis/repair, amino } \\
\text { acid metabolism }\end{array}$ & CDC47, PRO1 & $20 \%$ \\
\hline Yhp1 & 96 & 129 & $\begin{array}{l}\text { Cytokinesis, DNA } \\
\text { synthesis/repair, cell wall } \\
\text { synthesis }\end{array}$ & IQG1, CDC54, ECM14 & $22 \%$ \\
\hline Yox1 & 229 & 320 & $\begin{array}{l}\text { Spindle assembly, DNA } \\
\text { synthesis/repair }\end{array}$ & SPC72, RAD51 & $16 \%$ \\
\hline SBF & 163 & 183 & $\begin{array}{l}\text { Cell wall synthesis, DNA } \\
\text { synthesis/repair, polarized } \\
\text { growth, cell cycle regulation }\end{array}$ & FKS1, RNR1, GIN4, CLN2 & $66 \%$ \\
\hline $\mathrm{MBF}$ & 86 & 98 & $\begin{array}{l}\text { DNA synthesis/repair, cell wall } \\
\text { synthesis }\end{array}$ & POL1, DPM1 & $68 \%$ \\
\hline
\end{tabular}

ing major functional categories: polarized growth/morphogenesis/cytokinesis; DNA synthesis/repair; chromosome structure/segregation; cell cycle control and mitosis; meiosis and sporulation; plasma membrane synthesis; cell wall synthesis; transcription; protein synthesis; protein degradation; stress response; and energy generation. The Saccharomyces Gene Regulatory Network's Web site (http://array.mbb.yale.edu/yeast/transcription) contains a complete list of the gene targets of all of the transcription factors in this study, as well as the observed enrichments for each MIPS subcategory among the gene targets over the genomic prevalence of these functional categories.

The distribution of Hcm1, Plm2, Pog1, Tos4, Tos8, Tye7, Yap5, Yhp1, and Yox1 targets in these major categories are represented in Figure 6 and Table 1. Figure 6 also shows the enrichment of the specific subcategories over their genome prevalence for some of these factors. Collectively, and even individually, the transcription factors target a wide variety of cellular processes, especially those involved in early cell cycle events such as budding, spindle pole duplication, and DNA synthesis. Nonetheless, the proportion of target genes devoted to each functional category varies among the different factors and major functional roles of the factors are evident.
Several transcription factors target a large proportion of genes involved in polarized growth

Immediately following the START of the cell cycle, bud growth begins. A multitude of genes involved in several pathways and functional processes coordinate to promote polarized bud growth. Morphogenic and cell wall integrity pathways help to govern polarization of the actin cytoskeleton, secretion of cell wall and plasma membrane components, and cell wall synthesis. Many of the transcription factors downstream of SBF bind the promoters of genes involved in these processes. These include Tos8, Hcm1, Yhp1, Pog1, and Tos4.

Nearly $20 \%$ of Tos 8 target genes are devoted to some aspect of polarized growth. The chIp-chip analysis reveals that it binds upstream of BUD9 and BUD25, which both play a role in selecting a site for bud emergence in diploid cells but are known to be expressed in haploid yeast, as well. Tos8 also binds promoters of genes important for polarization of the actin cytoskeleton and bud emergence, such as BEM3 and BNI4.

A large proportion of $\mathrm{Hcm} 1$ target genes are also involved in bud growth, although they are mostly involved in cell wall synthesis and vesicular trafficking. Over $22 \%$ of $\mathrm{Hcm} 1$ targets have predicted functions in the synthesis of the cell wall. These include some structural 
Horak et al.

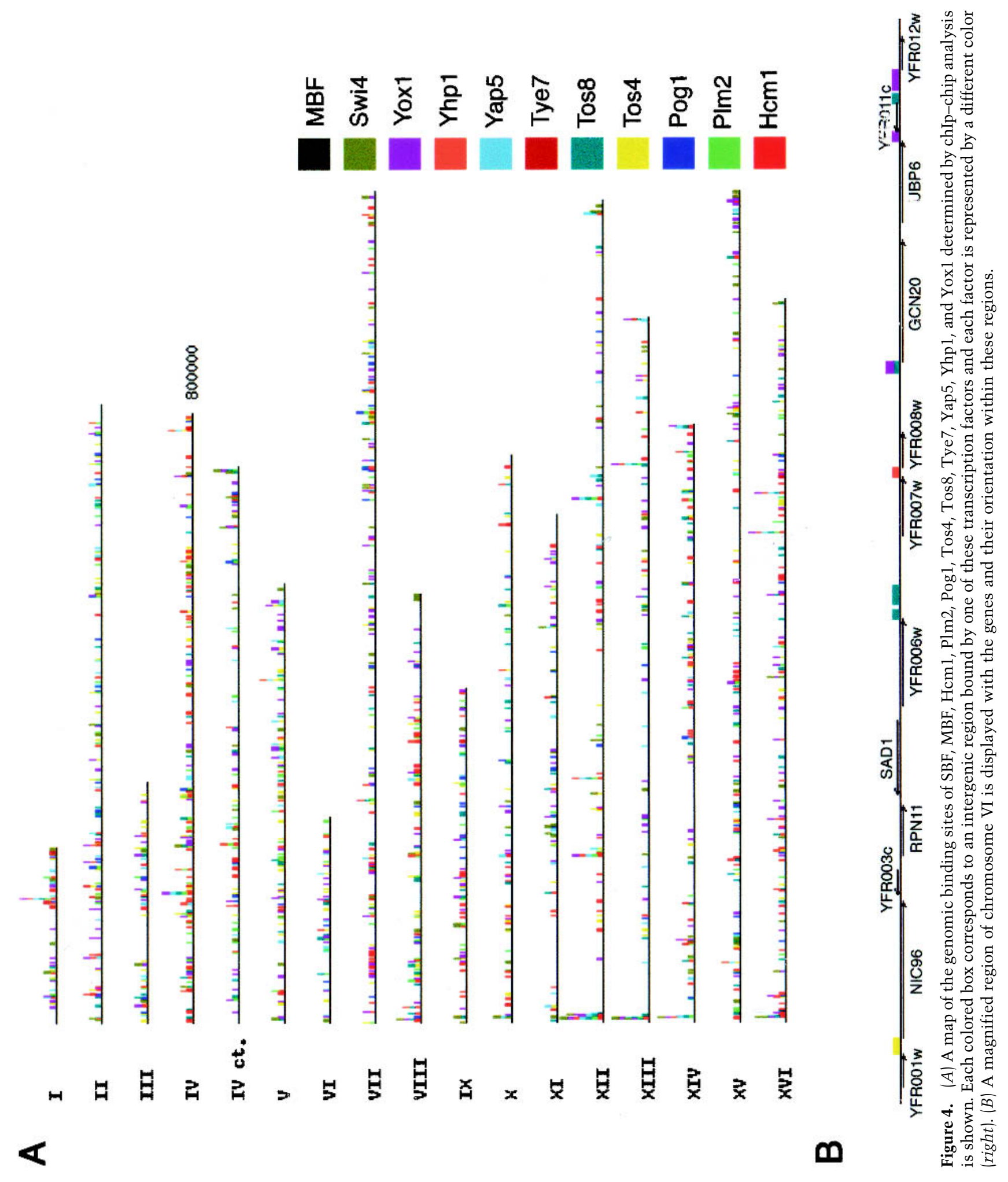




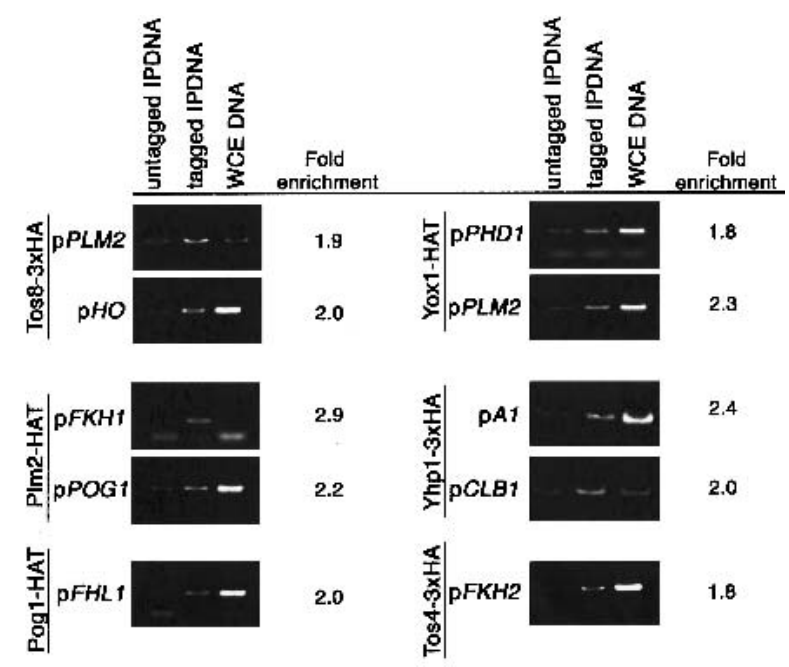

Figure 5. PCR assays confirm chIp-chip data for several transcription factors. Primers against the indicated promoter regions were used to amplify DNA immunoprecipitated with HA antibody from either a tagged strain of Tos8, Plm2, Pog1, Yox1, Yhp1, or Tos4 (lane 2) or untagged strain (lane 1). DNA purified from whole-cell extract was used as a positive control in each assay (lane 3). The relative enrichments of the amplified products from immunoprecipitates of the tagged strain vs. the untagged control are provided.

proteins, such as ECM14, but 28 of Hcml gene targets were either involved in carbohydrate metabolism, such as KRE11, or carbohydrate transport, like HXT15. Many of the Hcm 1 targets are important for vesicular transport and trafficking from the endoplasmic reticulum to the Golgi apparatus, which may influence cell wall, as well as plasma membrane organization. Much like Hcml, Yhp1 binds the promoters of many genes encoding cell wall structural proteins and components of the secretory pathway, which presumably function in cell wall deposition.

Hcm 1 also binds upstream of several genes important for cytoskeletal organization, including BNI1 and TPM1, which presumably act to polarize the cytoskeleton and vesicular trafficking to promote bud growth. Pog1 targets are also enriched for genes that function in cytoskeletal organization, such as the actin gene itself, $A C T 1$, and the actin-related protein $A R P 4$.

Tos4 also binds the promoters of a large percentage of genes $(13 \%$; Fig. 6$)$ that play a role in polarized growth, but most of these genes specifically participate in the pheromone response and mating. A total of 14 genes that mediate the pheromone response were identified as Tos4-binding targets including STE12, a transcription factor that regulates genes required for mating; FUS1, important for cell-cell fusion; $K A R 9$, which participates in karyogamy; and FIG2 and AFR1, which are involved in mating projection formation.

Many genes involved in DNA synthesis and repair are targets of transcription factors downstream of SBF

DNA synthesis also commences just after START progression and is coincident with the process of bud emer- gence. Many genes are involved in the process of replicating the genome and monitoring the fidelity of replication. Four of the factors downstream of SBF bind to a significant proportion of genes important for this process: Plm2, Yhp1, Yox1, and Yap5.

Eighteen percent of Plm2 targets are involved in DNA replication and repair. The $\mathrm{Plm} 2$ targets $O R C 5$ and $S L D 2$, genes involved in DNA replication; $C H K 1$, a gene important in the DNA-damage checkpoint; and RAD28, which is involved in DNA repair. Yox1 binds upstream of nearly 30 genes that are important for DNA synthesis and repair. It binds upstream of the ribonucleotide reductase genes RNR3 and RNR4, as well as several other promoters for genes involved in the DNA-damage response. Yox1 may also contribute to chromosome structure in that it binds the promoters of the histone genes HHT2 and HHF2 and the histone transcriptional regulator HIR2. The homolog of Yox1, Yhp1, also binds the promoters of genes important for DNA synthesis including CDC54, which is important for the initiation of replication and genes involved in the DNA damage response and repair. Many of Yap5 putative gene targets are also involved in aspects of the DNA damage response, including $R A D 4$, and chromatin remodeling, such as SIR4.

\section{Genes involved in mitotic functions are enriched among several transcription factor target genes}

SPB duplication, which is essential for nuclear division, is concomitant with the G1/S transition. Mitosis and nuclear division obviously occur much later in the cell cycle, but genes important for these processes are often expressed at earlier time points to prepare for these crucial events by positioning and ensuring the integrity of the spindle. The factors downstream of SBF bind the promoters of many genes involved in SPB duplication, spindle assembly and positioning, chromosome segregation, and mitosis. These include Hcm1, Pog1, Yox1, Yhp1, and Plm2.

There is a greater than twofold enrichment among Hcm 1 targets for genes that are involved in mitotic spindle activity and nuclear division. These include three known or predicted motor proteins that associate with microtubules: $C I N 8$, the kinesin involved in maintenance of the mitotic spindle; KIP3, another kinesin that bind cytoplasmic microtubules and is important for nuclear migration; and TID3, which is similar to myosin and localizes to the spindle pole. Perhaps, the Hcm 1 has a role in regulating these motor proteins, which may explain why hcm1s mutants are sensitive to benomyl, a microtubule-depolimerizing agent (data not shown). Hcm 1 binds upstream of other genes involved in spindle function and nuclear division, including the protein important for spindle elongation, $A S E 1$, and the kinase $C D C 15$, which regulates late nuclear division.

Pog1 is enriched nearly fivefold for targets involved in spindle organization compared with the genomic prevalence of this functional category. These Pog1 target 

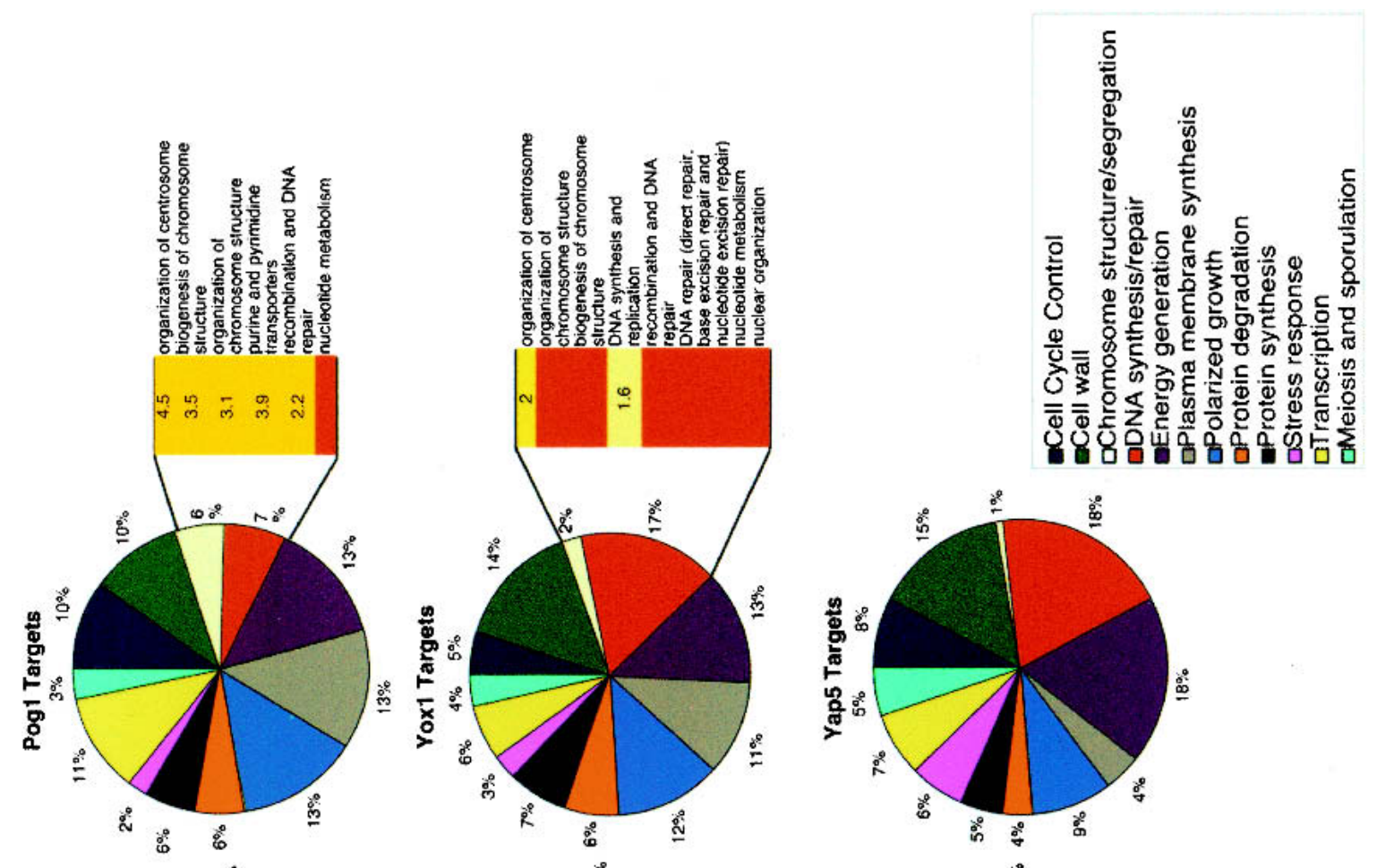

군

办.

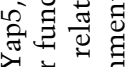

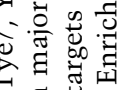

or

的交的

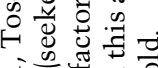

$\overrightarrow{0}, \overrightarrow{0}$

응 둥

है

. 目园

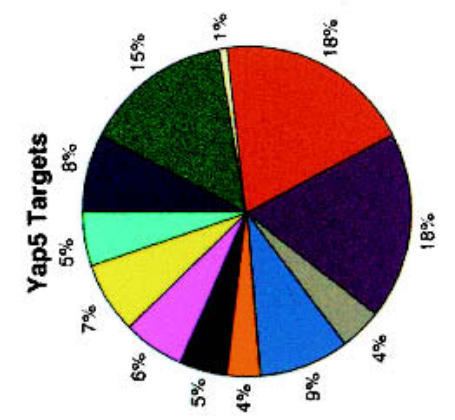

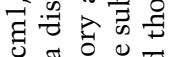

空

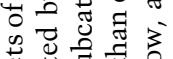

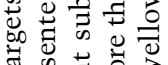

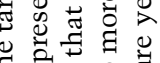

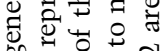

里苞芯
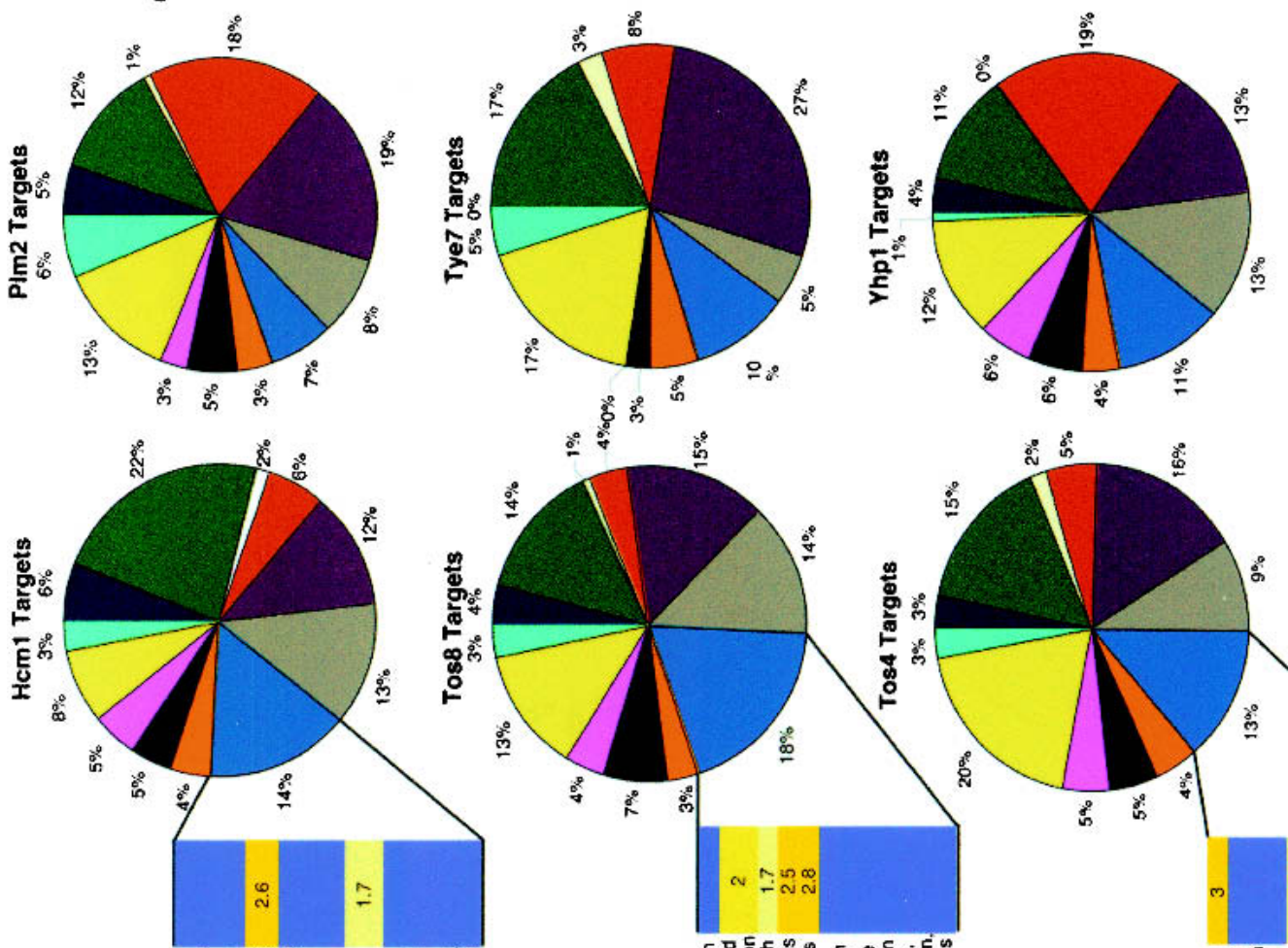

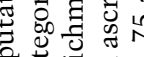

氜苛

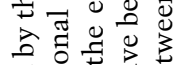

可

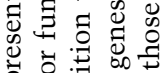

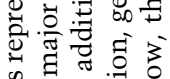

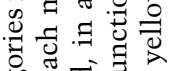

品导寻

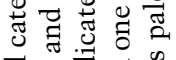

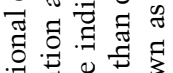

总矛语

灵苛

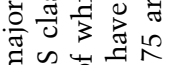

步㟔矛

表节司

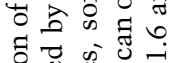

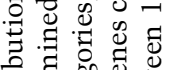

青品品

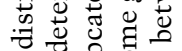

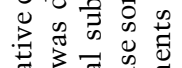

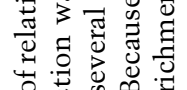

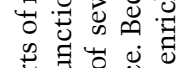
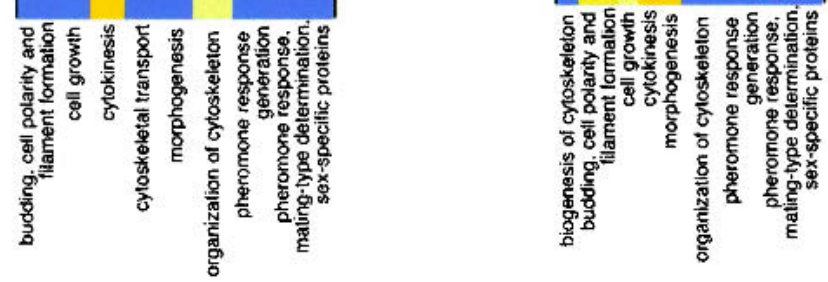

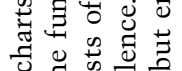

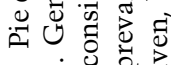

的㐫全呈

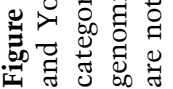


genes include SPC19 and MIF2, which are both components of the spindle pole. Like Pog1, Yox1-binding targets are also enriched for genes involved in spindle pole function. It binds upstream of a different group of genes encoding SPB components, including the SPC42 and $S P C 72$. Genes required for completion of mitosis are also targets of Yox1. Unlike Yox1 and Pog1, Yhp1 does not target genes of the SPB complex. It binds promoters of genes involved in other mitotic functions, such as IQG1, which is involved in cytokinesis, MCD4, which functions in the morphogenic checkpoint before mitotic onset, and KAR9, which is participates in nuclear migration. Plm2 also targets genes related to nuclear division, such as STU1 and CDC37, important for spindle function, and $M A D 2$, a component of the spindle integrity checkpoint. Interestingly, many of the Plm2 targets have roles in chromosome segregation as well.

\section{Many of Tye7 and Yap5 targets are involved in energy generation}

Whereas most of the transcription factors in this study contribute to the specific events that occur during the G1/S transition, some factors may participate in the more general roles of metabolism and respiration, which are also very important for cell growth. For example, 12 Yap5 targets participate in amino acid metabolism, which is a higher proportion relative to any other transcription factor in this study. Tye7 gene targets are enriched for genes involved in mitochondrial and peroxisomal function. Five of the 38 putative gene targets of Tye 7 are involved in mitochondrial functions, including YFH1 and PPA2 (see Discussion). In addition, Tye7 is enriched for genes important for sporulation and germination, which include YSW1 and SPO70 (see Discussion).

\section{Transcription factors downstream of SBF bind} promoters of genes involved in proteolysis

Ubiquitin-dependent proteolysis is crucial for progression into the G2 phase of the yeast cell cycle. It has been shown that this is important for degradation of the G1 cyclins in addition to Sic1, which inhibits $\mathrm{Clb} / \mathrm{Cdc} 28$ activity (Schwob et al. 1994; Verma et al. 1997). SBF did not bind upstream of any genes involved in proteolysis and MBF bound the promoters of only two such genes, the ubiquitin ligase, RSP5, and the proteasome subunit, PUP3. In addition, there was also no obvious enrichment for proteolytic genes among the Hcm1, Plm2, Pog1, Tos4, Tos8, Tye7, Yap5, Yhp1, and Yox1 gene targets; however, together they bind upstream of 15 additional genes involved in ubiquitin-dependent proteolysis. Tos4 target genes include the E1 activating enzyme, UBA1, the E2 conjugating enzymes, $U B C 4$ and $U B C 8$, and the proteasome subunit PRE1. Yox1 binds promoters for $A O S 1, U B C 6$, and the proteasome subunits, PRE9 and $U B P 2$, and Tos8 binds the promoter of RPN10, another proteosomal subunit. The E3 ligase UBR1 and the pro- teasome subunit RPN7 are targets of Pog1. CDC4 and SKP1, the F-box-containing E3 ligases are targets of Tos8 and $\mathrm{Plm} 2$, respectively.

Many target genes are involved in cell cycle regulation

SBF and MBF are critical for the START of the cell cycle because they up-regulate the expression of the G1- and S-phase cyclin genes (Dirick et al. 1992; Koch et al. 1993; Cross et al. 1994). They also bind the promoters of other genes important in cell cycle and CDK regulation (Iyer et al. 2001). Relative to the other transcription factor targets of SBF, Pog1 targets the highest proportion of genes with roles in cell cycle regulation $(11 \%)$, a proportion similar to SBF (Fig. 6). Pog1 binds the promoters of GIF1, which is critical for the G1 phase; CKS1, which encodes a protein that associates with the major cyclin-dependent kinase, Cdc28; CKA1, the catalytic subunit of casein kinase II; and BUB1, a component of the mitotic checkpoint in response to spindle defects. Also interestingly, Pog 1 binds upstream of $B A R 1$, the $\alpha$ factor protease (see Discussion).

With the exception of Tye7, all of the other factors in this study bind to the promoters of genes involved in cell cycle regulation. Four of the factors target G1 cyclins: Hcm1 binds upstream of CLN3, Tos8 and Plm2 bind the PCL2 promoter, and Yox1 binds upstream of CLN2. Yox1 also targets the S-phase cyclin gene CLB6 and Yhp1 binds the G2 cyclin gene CLB1. PHO85, the gene encoding the other yeast cyclin-dependent kinase, is a target of Yap5.

Interestingly, $\mathrm{Hcm} 1$ binds to the promoters of three genes that have human homologs that are known tumor or cancer-related genes. These targets include the yeast gene TEP1, whose human homolog is the tumor suppressor PTEN; YHLO1Oc, an uncharacterized gene related to BRAP2, a breast cancer-associated gene; and YHR114W, which is related to the VAV oncogene. Given that their human homologs are involved in cellular proliferation, these $\mathrm{Hcm} 1$ target genes may also participate in cell cycle regulation.

\section{Cell cycle periodicity of targets}

SBF and MBF are known to regulate the periodic expression of genes early in the cell cycle (Nasmyth and Dirick 1991; Ogas et al. 1991; Dirick et al. 1992; Lowndes et al. 1992; Koch et al. 1993; Cross et al. 1994). In fact, $50 \%$ of both MBF and SBF promoter targets are upstream of a gene with peak transcript profiles in G1 or S phase (Iyer et al. 2001). A total of $5.6 \%$ of all yeast genes peak in expression at this point within the cell cycle, so SBF and MBF target genes are enriched ninefold for G1/S genes. Together SBF and MBF bind $21 \%$ of these G1/S-specific genes.

The cell cycle expression profiles of target genes of the transcription factors downstream of SBF were examined to determine whether they are enriched for G1/S-specific genes, as well. The results of this analysis are illustrated 
in Figure 7. Together all of the factors analyzed in this study bind intergenic regions adjacent to an additional $21 \%$ of genes with peak transcript levels in the G1 or S phases of the cell cycle. The targets for only five of these factors are enriched for targets with peak expression in $\mathrm{G} 1 / \mathrm{S}$ and the observed enrichment is not as striking as that observed for SBF and MBF. Ten percent, 11\%, 14\%, and $15 \%$ of promoters bound by Yox1, Tos8, Yap5, and Yhp1, respectively, neighbor G1-specific genes. Pog1 and Tos 4 bind regions neighboring $4.1 \%$ and $4.2 \%$ of genes with peak transcript levels in $S$ phase, respectively, which is a relative enrichment of fourfold over the prevalence of S-phase genes in the genome. The gene targets of these two factors are also enriched for genes that peak at S/G2, and Tos4 putative gene targets are additionally enriched for G2/M-specific genes, suggesting that these

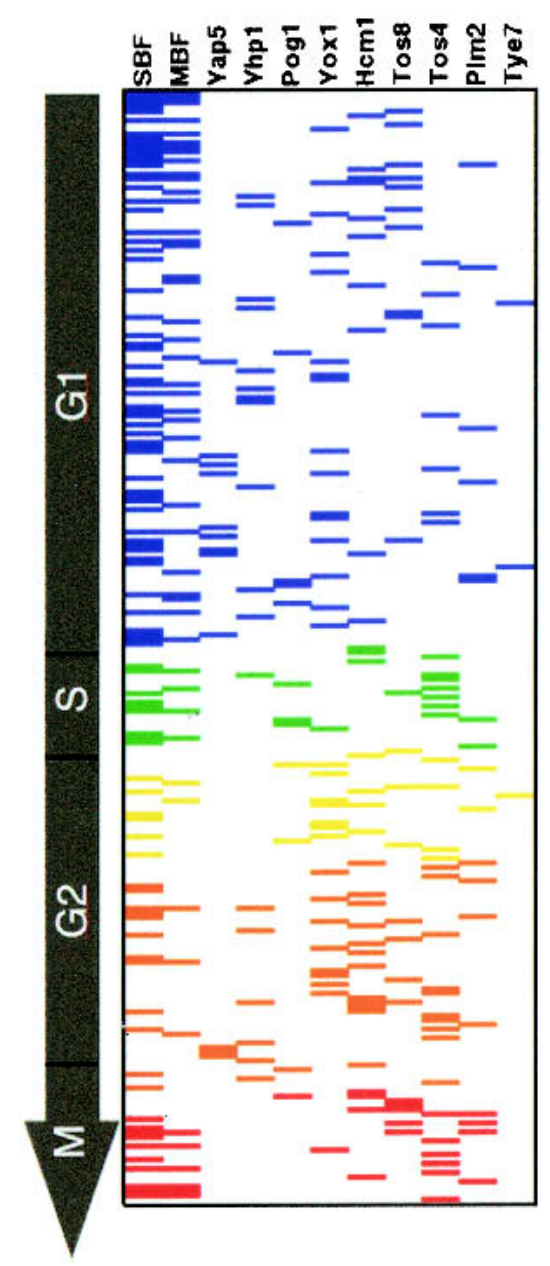

Figure 7. A total of 248 gene targets with cell cycle periodicity of expression were the targets of SBF, MBF, Hcm1, Plm2, Pog1, Tos4, Tos8, Tye7, Yap5, Yhp1, and Yox1 combined. Each of these genes is depicted as a row in this diagram and a colored box means that it is a putative target of the transcription factor indicated in the corresponding column heading. The color of the box is representative of the phase in the cell cycle where the gene's transcript levels peak: blue, G1; green, $\mathrm{S}$; yellow, S/G2 transition; orange, G2/M transition; red, M/G1. factors may be important for the periodicity of genes slightly later in the cell cycle (see Fig. 7). Together SBF, MBF, Hcm1, Plm2, Pog1, Tos4, Tos8, Tye7, Yap5, Yhp1, and Yox 1 bind adjacent to $42 \%$ of genes with peak expression in G1/S and one-third of all cell cycle-regulated genes.

Sixteen percent and $18 \%$ of SBF and MBF targets genes, respectively, peaked in expression at other points in the cell cycle. Many of the targets of the transcription factors downstream of SBF also peak at other times in the cell cycle. In fact, combined these factors target 2.5fold more of these genes that peak outside of G1/S relative to SBF and MBF. Genes neighboring promoter regions bound by Tos 8 and Hcm 1 are threefold enriched for $M / G 1$ and G2/M genes, respectively. Thus, these various factors probably not only control genes expressed early in the cell cycle, but they may also regulate genes expressed at later times as well.

\section{Overlapping targets among the transcription factors}

As the transcription factors analyzed in this study are all downstream of SBF and some share overlapping functional roles, some of their gene targets may be identical. In addition, some of their targets may overlap with SBF and MBF targets as part of a positive or negative feedback loop. Table 2 shows the number of putative target genes shared by the factors that were studied and Swi4 and MBF.

For the most part, there is very little overlap between $M B F$ and the rest of the factors that are binding targets of SBF. With SBF, too, there are very few shared targets with these factors; Tos 8 shares the most with 17 targets. A closer look at these Tos8 targets shared with SBF, which include $H O, P C L 2, P L M 2$, and BUD9, indicates that they do not fall into any obvious functional groups, much like the targets shared by SBF and MBF, which include transcription factors, DNA replication genes, cyclins, and cell wall synthesis genes.

There are two pairs of homologs among the transcription factor genes downstream of SBF: Plm2 and Tos4, and Yhp1 and Yox1. Although Tos4 has the greatest number of genes shared with its homolog Plm2 (19), $\mathrm{Plm} 2$ seems to have more common targets with the forkhead-like transcription factor Hcml (26). The homeodomain-containing transcription factors, Yhp1 and Yox1, share very few common targets, which may not be surprising given that their expression is somewhat offset. Yox1 does, however, share a significant number of targets with Tos8, another transcription factor with a homeodomain.

Hcml shares $>20$ targets with several other factors, including Tos8, Plm2, Yap5, Yhp1, and Yox1. Some of these are the subtelomeric sequences that are targets of all six of these factors (see Fig. 4), but others are uniquely overlapping with Hcm 1 . Perhaps, even more significantly, Tye7 and Pog1 have very little overlap with any other factor, reflecting their unique functional roles. Thus, in conclusion, most of the transcription factors are unique sets of genes. In cases where transcription factors 
Table 2. Common gene targets of transcription factors

\begin{tabular}{|c|c|c|c|c|c|c|c|c|c|c|c|}
\hline & Hcm 1 & $\mathrm{Plm} 2$ & Pog1 & Tos4 & Tos8 & Tye7 & Yap5 & Yhp1 & Yox1 & $\mathrm{MBF}$ & Swi4 \\
\hline Hcm 1 & 262 & 26 & 3 & 9 & 52 & 2 & 27 & 22 & 30 & 9 & 11 \\
\hline $\mathrm{Plm} 2$ & & 197 & 8 & 19 & 23 & 1 & 21 & 21 & 24 & 5 & 6 \\
\hline Pog1 & & & 96 & 3 & 0 & 4 & 0 & 3 & 8 & 1 & 0 \\
\hline Tos4 & & & & 230 & 10 & 4 & 13 & 9 & 17 & 3 & 6 \\
\hline Tos8 & & & & & 256 & 2 & 26 & 17 & 37 & 14 & 22 \\
\hline Tye7 & & & & & & 38 & 3 & 2 & 5 & 1 & 1 \\
\hline Yap5 & & & & & & & 147 & 16 & 24 & 9 & 10 \\
\hline Yhp1 & & & & & & & & 129 & 17 & 6 & 5 \\
\hline Yox1 & & & & & & & & & 320 & 15 & 18 \\
\hline MBF & & & & & & & & & & 95 & 46 \\
\hline Swi4 & & & & & & & & & & & 172 \\
\hline
\end{tabular}

Number of gene targets overlapping between 2 transcription factors are shown at their intersection. (Light gray boxes) The largest number of overlapping targets for one of the transcription factors; (dark gray box) the largest number of overlapping targets in this analysis.

do overlap there might be multiple and perhaps redundant regulation.

\section{Transcription factor network}

Together SBF and MBF bind upstream of 16 genes encoding transcription factors. Therefore, although they only bind to 235 gene promoters directly, they may influence the transcription of thousands of genes through these downstream factors. These transcription factors in turn bind to the promoters of still more transcription factorencoding genes. For six of these factors, $>10 \%$ of the known targets play a role in transcription (Plm2, Pog1, Tos4, Tye7, and Yhp1). In Figure 8, we show the start of a comprehensive network of transcription factors using the in vivo binding data of our chIp-chip analyses. A number of these interactions have been confirmed by independent PCR assays (see Figs. 1, 5).

There is the potential for feedback onto SBF and MBF, as Swi4 binds its own promoter and is also bound by MBF. In addition, Tos 4 binds the SWI6 promoter, which encodes the regulatory component of both SBF and MBF. These targets of SBF also interact with each other. The Plm2 promoter is bound by Tos 8 and Yox 1 as well as SBF. The relevance of this is not clear but may reflect a need to precisely regulate the levels of this protein under different cellular conditions. Plm2 binds another target of SBF, the POG1 promoter.

Further analysis of the transcription factor targets reveals that the transcription factors in this study are potentially capable of regulating all of the promoters of transcription factor genes that have peak transcript levels at G1/S. Swi4 binds NDD1, PLM2, HCM1, YOX1, YHP1, SPT21, and TOS4 promoters. Yhp1 and Plm2 each bind regions adjacent to the two G1/S anti-silencing factor genes, ASF1 and ASF2, respectively. Yox1 binds the promoters of two other of G1/S-specific genes involved in cellular differentiation, PHD1, a transcription factor involved in pseudohyphal growth, and $R M E 1$, involved in meiosis, and Hcm 1 binds the STB1 promoter. Thus, this network describes at least one interaction for every G1/S-regulated transcription factor.
Interactions between the SBF targets and transcription factors that are important in cell cycle regulation and which act or have peak transcript levels later in the cell cycle are also apparent. Both Plm2 and Hcm1 bind the Fkh1 promoter, which is known to bind the promoter of CLB4, which encodes a G2 cyclin (Simon et al. 2001). FKH1 itself has peak expression at the S/G2 transition. Tos 4 binds the promoter of a related gene, FKH2, the product of which is known to regulate the expression of another G2 cyclin, CLB2 (Koranda et al. 2000; Kumar et al. 2000; Pic et al. 2000; Zhu et al. 2000). POG1, MIG2, and the ALPHA1 and ALPHA2 transcription factor genes, which all peak in expression during the G2/M transition, are bound by $\mathrm{Plm} 2, \mathrm{Hcm} 1$, and Tos4, respectively. Yap5 and Tos4 bind TSM1 and TEC1 promoters, respectively, which peak at M/G1 (Spellman et al. 1998). These cascades of cell cycle regulated transcription factors may be an important force in propelling the cell cycle.

\section{Discussion}

\section{Regulation of the G1/S genes}

SBF and MBF, two factors that are critical for the START of the yeast cell cycle, have been shown to bind 235 gene promoters (Iyer et al. 2001). Only $21 \%$ of the G1/S genes are accounted for among these downstream target genes and, in addition, genes involved in spindle pole assembly, DNA synthesis, and ubiquitin-dependent proteolysis, all of which are important G1/S events, are underrepresented as $\mathrm{SBF} / \mathrm{MBF}$ targets. However, among those SBF and/or MBF targets were 16 transcription factors, which may regulate the expression of genes in these under-represented functional categories and G1/S transcript periodicity. We identified the binding targets of nine of these factors by chIp-chip analysis (Hcm1, Plm2, Pog1, Tos4, Tos8, Tye7, Yap5, Yhp1, and Yox1) to learn more about the regulatory network of the G1/S transition and how the complex events of this period are controlled.

On average, these factors bind $\sim 120$ promoters. To- 
Horak et al.

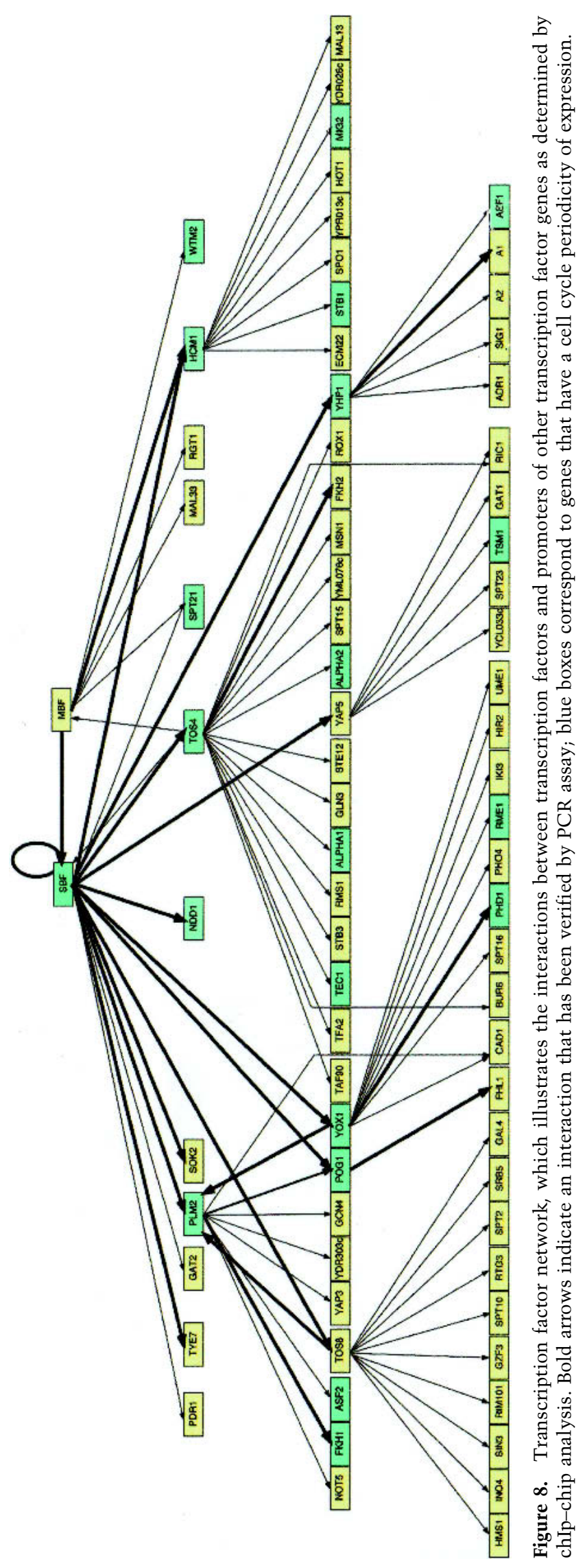


gether they bind the promoters of another $21 \%$ of the G1/S-induced genes and a total of 150 genes that are cell cycle regulated. Some of the factors target more G1/Sspecific genes and/or more cell cycle-regulated genes than others in this study. Yhp1, Yap5, and Yox1 bind many promoters adjacent to genes with peak transcript levels in G1, whereas Tos4 and Pog1 bind upstream of many genes with peak expression slightly later in the cell cycle at S/G2. Yhp1, along with Hcm1, targets a large proportion of genes with expression peaking around mitosis. Thus, these factors may contribute to G1/S periodicity of expression, but perhaps a more salient conclusion is that they may contribute to the subsequent waves of expression in the cell cycle.

These results also indicate that the timing of expression of a transcription factor does not necessarily relate to the timing of expression of its target genes. Plm2, Tos4, and Yox1 are all induced in G1. Whereas many putative gene targets of Yox1 peak in G1, many Tos4 targets peak around the G2 phase and Plm2 does not target a significant proportion of genes that are cell cycle regulated. Post-transcriptional modification, signaling pathways, and combinatorial control with other factors presumably influence the timing of transcriptional activity of any given transcription factor. In addition, these factors may act to repress gene expression at particular points in the cell cycle to affect the periodicity of its gene targets.

A total of $58 \%$ of G1/S genes are not a target of any of the factors in this study or of SBF/MBF. These other genes that are expressed specifically in G1/S may be targets of the other transcription factors downstream of SBF and MBF or other transcriptional or translational regulators. Because the targets of the SBF, MBF, Plm2, Yhp1, and Yox1 account for all G1/S-regulated transcription factors, it is likely that identification of the targets of all of these factors by chIp-chip may account for nearly all G1/S-regulated genes.

Within this study, we explored only transcription factor binding and did not analyze transcript levels in transcription factor mutants. We have carried out microarray expression analysis of some deletion mutants of these transcription factors (data not shown), but in some cases targets are not significantly affected, presumably because of transcriptional redundancy. Alternatively, as many of the transcription factors in this study are implicated in cell cycle regulation, they may affect the timing of expression in the cell cycle rather than absolute levels. Therefore, small differences in mRNA expression could be quite relevant. Verifying their effects on timing of expression requires transcriptional profiling throughout the cell cycle, which is not a trivial effort.

\section{Functional roles of factors at G1/S}

Putative gene targets of SBF and MBF, as determined by chIp-chip analysis, had roles in three major functional categories: bud growth, cell cycle control, and DNA synthesis/repair, all of which are relevant to the events early in the yeast cell cycle (Iyer et al. 2001). The transcription factors downstream of SBF also bind the promoters of many genes classified in these three major categories.
However, these factors target genes that are involved in another major functional class-mitosis and nuclear division. This functional category subsumes the more specific functional classes of SPB duplication, spindle elongation, chromosome segregation, nuclear migration and division, and cytokinesis. Many of these activities either transpire around the G1/S transition or the genes important for these processes are expressed at this time. The targets of the factors downstream of SBF then account for some functional roles that were not well-represented among $\mathrm{SBF} / \mathrm{MBF}$ target genes.

In addition, some of the factors downstream of SBF bind the promoters of a significant proportion of genes with roles in the differentiation processes of mating, mating typing, filamentous growth, and sporulation. This suggests that these factors are important in executing differentiation programs in response to particular external stimuli or internal cues around the G1-to-S-phase transition. Thus, although SBF and MBF have limited functional roles, transcription factors downstream of them contribute to other events linked to START.

\section{Functional specificity of transcription factors}

Although the major functional categories of genes can be found among all of these transcription factors' targets, careful examination of the relative enrichment of specific functional categories compared with their genomic prevalence reveals functional distinctions for the factors as discussed in the Results section. Importantly, the analysis of the targets of the different transcription factors helps explain previously reported observations regarding the various factors.

For example, Tos 4 targets are enriched for pheromone response genes and this factor binds upstream of several prominent genes involved in mating. This finding is consistent with the evidence that TOS4 expression is repressed by the mating pheromone $\alpha$ factor (Breitkreutz et al. 2001). Tos4 may act to repress the pheromone response genes during the cell cycle and in the presence of $\alpha$ factor, repression of Tos 4 may result in the derepression of genes of the mating pathway.

Pog1 may also participate in repression of the mating response. When this transcription factor is overexpressed, it can inhibit the mating response pathway in the presence of $\alpha$ factor and promote cell cycle progression (Leza and Elion 1999). Although the targets of Pog1 are not enriched for genes involved in the pheromone response pathway, it does bind upstream of $B A R 1$, the secreted $\alpha$ factor protease (see Table 1). This may explain how POG1 overexpression confers pheromone resistance. Pog1 also binds upstream of and presumably regulates the expression of genes important for cell cycle progression, suggesting a mechanism by which Pog1 overexpression can promote vegetative growth even in the presence of $\alpha$ factor.

Putative Tye7 targets are enriched for genes involved in sporulation, consistent with the observation that Tye7 null mutants are defective in sporulation. However, Tye7 is predicted to regulate expression of genes encoding enzymes of the glycolytic pathway, such as the 
enolases ENO1 and ENO1 because their expression is altered in a tye $7 \Delta$ mutant (Nishi et al. 1995; Sato et al. 1999). We did not observe Tye7 binding of the ENO1 and ENO2 promoters as predicted, but we find that it does bind upstream of genes involved in mitochondrial function and respiration and may thereby indirectly affect the expression of genes of the glycolytic pathway.

The Tos 4 homolog, Plm2, shares some targets with Tos4, but it appears to have a distinct functional role in the DNA damage and repair pathways. Microarray expression studies support a role for Plm2 in these pathways as PLM2 gene expression is activated by DNA damage (Gasch et al. 2001). This activation may in turn result in the activation of genes of the DNA damage checkpoint and DNA repair.

Our data implicate Hcm1, the forkhead transcription factor, in regulation of genes encoding microtubule motors of the spindle apparatus and other spindle-associated proteins. This finding is supported by phenotypic evidence. $h c m 1 \Delta$ mutants are sensitive to the microtubuledepolymerizing drug benomyl and a point mutation in hcm1 specifically suppresses the spindle defects of a point mutation of calmodulin (Zhu and Davis 1998).

Our data are also supported by published findings for Yox1 and Yhp1. Yox1 binds upstream of many genes involved in spindle function and DNA synthesis and repair, but we also find that it binds $10 \%$ of intergenic regions neighboring tRNA genes, including three leucine tRNA genes, which have been shown to be specifically bound by Yox1 using in vitro binding assays (Kaufmann 1993). Recently, phenotypic analysis revealed that yox $1 \Delta y h p 1 \Delta$ double mutant cells bud at a smaller size, which is consistent with our finding that Yoxl binds the promoters of several genes that regulate G1 cyclin activation, including RME1, SPT16 and BCK2 (Pramila et al. 2002). In addition, this study found the expression of 28 genes to be affected by Yox1 overexpression and Yox1 and Yhp1 depletion. Several of our Yox1 and Yhp1 targets overlap with these genes and, interestingly, those that do overlap fall into a specific class of genes whose expression is still periodic, but expressed over a broader time interval in the cell cycle in yhp1syox $1 \Delta$ mutants (Pramila et al. 2002). Other genes identified in this study may be affected indirectly through transcription factors downstream of these homeodomain transcription factors.

Published data is also consistent with the results of Tos 8 chIp-chip analysis. The major functional category of Tos 8 targets are involved in bud growth including several genes important for bud site selection and bud emergence. A multicopy plasmid containing the TOS 8 gene was observed to enhance the random budding pattern of a bud3s mutant in haploids (Freedman et al. 2000). Whereas the Tos 8 bud site selection target genes are implicated in diploid site selection, their misregulation may influence haploid budding. In addition, altered expression of bud emergence genes may also upset the process of bud site selection.

One apparent discrepancy between our results and published results is that Yhpl is predicted to play a role in meiosis because of its reported interaction with the promoter of $I M E 1$, a transcription factor that induces genes in early meiosis (Kunoh et al. 2000). We did not find the IME1 promoter as a target of Yhp1, but all the chIp-chip assays were performed with a haploid strain, which cannot undergo meiosis. Yhpl could bind different promoters in haploid and diploid backgrounds.

Thus, in conclusion, each of the transcription factors analyzed in this study appear to have distinct functional roles based on their putative target genes identified by chIp-chip analysis. These presumed functional distinctions are largely consistent with evidence reported in the literature.

\section{Complex transcriptional network}

Many of the transcription factors that were targets of SBF in turn bind to the promoters of other transcription factor-encoding genes, creating a potential circuit of transcriptional activation. A striking feature of this network of transcription factors is that it is largely hierarchical: upstream factors regulate those downstream (Fig. 8). However, a few cases of feedforward (Tos 8 and Yox1 bind the PLM2 promoter; Plm2 binds the POG1 promoter), feedback (Tos4 binds the SWI6 promoter), and autoregulation (Swi4 binds its own promoter) exist. None of the transcription factors analyzed bind the SWI4 or MBP1 promoters, suggesting that if feedback regulation exists, positive or negative, it is mediated by other means. Consistent with this hypothesis, Swi4 DNA-binding activity is diminished by Clb2 protein (Amon et al. 1993). However, Tos 4 binds the SWI6 promoter and might indirectly affect the activity of SBF and MBF, as Swi6 is crucial for the capacity of Swi4 and Mbp1 to bind DNA (Moll et al. 1992; Primig et al. 1992; Harrington and Andrews 1996).

Another observation of the transcription factor network that emerges from our chIp-chip data is the amount of interaction between factors important for cell cycle regulation or that are themselves transcriptionally cell cycle-regulated. All those transcription factors whose transcript levels peak during G1 or S are part of this network and, in addition, factors that play a role in the next phase of the cell cycle may be regulated by transcriptional activity in a previous stage of the cell cycle. Thus, a transcriptional cascade of activation may contribute to cell cycle progression.

Many of the transcription factors with implied roles early in the cell cycle also bind promoters of many transcription factor genes that are critical for cellular differentiation. STE12, TEC1, A1, ALPHA1, ALPHA2, PHD1, and $R M E 1$ are all part of this circuitry. The convergence of all of these factors at this point in the cell cycle reflects the importance of this time for developmental decisions based on assimilation of environmental cues

Transcriptional cascades have been previously documented, particularly for transcription factors of pseudohyphal differentiation (Banuett 1998; Pan and Heitman 2000) and the cell cycle (Simon et al. 2001). The network of transcription factors that we present illustrates how a complex transcriptional circuit may work to manifest cellular proliferation and/or differentiation early in the yeast cell cycle. 


\section{Materials and methods}

Yeast strains, growth conditions, and construction of epitope-tagged strains

Yeast strains used in this study are listed in Table 3 and are isogenic with the S288c genetic background. Manipulations and growth conditions were as described (Sambrook et al. 1989). Yeast transformations were using the lithium acetate method (Ito et al. 1983).

HCM1, TOS4, TOS8, YAP5, and YHP1 were tagged with three copies of the hemagglutinin (HA) epitope tag at the $\mathrm{C}$ terminus using a PCR-based method and homologous recombination as descibed by Schneider et al. (1995). PLM2, POG1, TYE7, and YOX1 were tagged by means of transposon insertion containing the hemagglutinin epitope (HAT) coding (Ross-MacDonald et al. 1997). All strains were grown under rich growth conditions in yeast extract, peptone, adenine, and dextrose (YPAD) at $30^{\circ} \mathrm{C}$. SWI4-3XHA and MBP1-3xmyc strains have been described previously (Iyer et al. 2001).

\section{Protein immunoprecipitations and immunoblotting}

Lysates were prepared from a 50-mL culture of cells at $\mathrm{OD}_{600}$ of $0.5-0.8$. Cells were lysed by bead-beating in a $400-\mu \mathrm{L}$ lysis buffer containing $0.1 \%$ deoxycholic acid, $1 \mathrm{mM}$ EDTA, $50 \mathrm{mM}$ HEPES-KOH at pH 7.5, $140 \mathrm{mM} \mathrm{NaCl}, 1 \%$ Triton X-100, $1 \mathrm{mM}$ PMSF, and protease inhibitors (Sigma), an equal volume of cubic

Table 3. Yeast strains used in this study

\begin{tabular}{|c|c|c|}
\hline Strain & Genotype & Source \\
\hline Y1495 & $\begin{array}{l}\text { MATa ura3-52 lys2-801 ade2-101 } \\
\quad \text { trp1 } \Delta 1 \text { his3 } \Delta 200\end{array}$ & Iyer et al. (2001) \\
\hline Y1496 & $\begin{array}{l}\text { MATa ura3-52 lys2-801 ade2-101 } \\
\quad \operatorname{trp} 1 \Delta 1 \text { his3 } \Delta 200 \text { SWI4-3XHA }\end{array}$ & Iyer et al. (2001) \\
\hline Y1497 & $\begin{array}{l}\text { MATa ura3-52 lys2-801 ade2-101 } \\
\operatorname{trp} 1 \Delta 1 \text { his3 } \Delta 200 \\
\text { MBP1-3XMYC }\end{array}$ & Iyer et al. (2001) \\
\hline Y1498 & $\begin{array}{l}\text { MATa ura3-52 lys2-801 ade2-101 } \\
\quad \operatorname{trp} 1 \Delta 1 \text { his3 } \Delta 200 \\
\text { HCM1-3XHA }\end{array}$ & This study \\
\hline Y1499 & $\begin{array}{l}\text { MATa ura3-52 lys2-801 ade2-101 } \\
\text { leu2 } \Delta 98 \text { his3 } \Delta 200 \\
\text { PLM2-mTn61D3 }\end{array}$ & This study \\
\hline Y1500 & $\begin{array}{l}\text { MATa ura3-52 lys2-801 ade2-101 } \\
\text { leu2 } \Delta 98 \text { his3 } \Delta 200 \\
\text { POG1-mTn31E1 }\end{array}$ & This study \\
\hline Y1501 & $\begin{array}{l}\text { MATa ura3-52 lys2-801 ade2-101 } \\
\quad \operatorname{trp} 1 \Delta 1 \text { his3 } \Delta 200 \text { TOS4-3XHA }\end{array}$ & This study \\
\hline Y1502 & $\begin{array}{l}\text { MATa ura3-52 lys2-801 ade2-101 } \\
\text { leu2 } \Delta 98 \text { his3 } \Delta 200 \\
\text { TOS8-3XHA }\end{array}$ & This study \\
\hline Y1503 & $\begin{array}{l}\text { MATa ura3-52 lys2-801 ade2-101 } \\
\text { leu2 } \Delta 98 \text { his3 } \Delta 200 \\
\text { TYE7-mTn68C8 }\end{array}$ & This study \\
\hline Y1504 & $\begin{array}{l}\text { MATa ura3-52 lys2-801 ade2-101 } \\
\text { leu2 } \Delta 98 \text { his3 } \Delta 200 \\
\text { YAP5-3XHA }\end{array}$ & This study \\
\hline Y1505 & $\begin{array}{l}\text { MATa ura3-52 lys2-801 ade2-101 } \\
\text { leu2 } \Delta 98 \text { his3 } \Delta 200 \\
\text { YHP1-3XHA }\end{array}$ & This study \\
\hline Y1506 & $\begin{array}{l}\text { MATa ura3-52 lys2-801 ade2-101 } \\
\text { leu2 } \Delta 98 \text { his3 } \Delta 200 \\
\text { YOX1-mTn18C2 }\end{array}$ & This study \\
\hline
\end{tabular}

zirconium beads (Biospec Products, Inc.), and vortexing $8 \times$ in 1-min pulses, with 2-min incubation on ice between pulses. Lysates were incubated on ice for $15 \mathrm{~min}$ and transferred to a fresh microfuge tube; the beads were washed in an additional $400-\mu \mathrm{L}$ lysis buffer with $1 \mathrm{~min}$ of vortexing and combined with the lysate. Extracts were clarified by centrifugation at 14,000 $\mathrm{rpm}$ at $4^{\circ} \mathrm{C}$ for $15 \mathrm{~min}$.

Hcm1, Plm2, Tos4, Tos8, and Tye7 epitope-tagged proteins were immunoprecipitated for $3 \mathrm{~h}$ on ice using a monoclonal antibody that recognizes the hemagglutinin epitope, either 12CA5 (Babco) or 16B12 (Covance Research Products), at a 1:150 dilution. Immuncomplexes were purified by adding a $30-\mu \mathrm{L}$ bed volume of Protein-A sepharose beads (Pierce) and incubating with rocking at $4^{\circ} \mathrm{C}$ for $1 \mathrm{~h}$. Pog1, Yap5, Yhp1, and Yox 1 epitope-tagged proteins were immunoprecipitated using Protein Gsepharose beads cross-linked to anti-hemagglutinin 12CA5 antibody according to the Pierce Sieze X Yeast Immunprecipitation kit. The beads were washed $5 x$ in lysis buffer and then resuspended in $50 \mu \mathrm{L}$ of SDS-PAGE sample buffer.

Protein extracts were separated in a $10 \%$ denaturing polyacrylamide gel and analyzed by immunoblot analysis using a 1:1000 dilution of anti-HA primary antibody and a 1:5000 dilution of an alkaline phosphatase-conjugated secondary antibody. Immunocomplexes were visualized with the West Pico chemiluminescence system (Pierce).

\section{Chromatin immunoprecipitation}

For the isolation of chromatin, cells were grown in $100 \mathrm{mlL}$ of YPAD to an $\mathrm{OD}_{600}$ of $0.5-0.8$ and fixed with formaldehyde at a final concentration of $1 \%$ for $15-30 \mathrm{~min}$ at $25^{\circ} \mathrm{C}$. The chIp procedure was performed as described (Horak and Snyder 2002). Protein-DNA complexes were immunoprecipitated with either anti-HA $16 \mathrm{~B} 12$ or $12 \mathrm{CA} 5$ at a final dilution of 1:150.

\section{PCR Assays}

Immunoprecipitated DNA was analyzed for specific enrichment by PCR.

Primers sequences are available as Supplemental Material. A total of $10 \%-20 \%$ of immunoprecipitated DNA was amplified by PCR using $2 \times$ Taq Mastermix (QIAGEN) and the following thermalcycling conditions: $94^{\circ} \mathrm{C}$ for $2 \mathrm{~min}, 27$ cycles of $20 \mathrm{sec}$ at $94^{\circ} \mathrm{C}, 30 \mathrm{sec}$ at $50^{\circ} \mathrm{C}, 1 \mathrm{~min}$ at $72^{\circ} \mathrm{C}$, followed by a $10-\mathrm{min}$ extension time at $72^{\circ} \mathrm{C}$. Input DNA from sonicated lysate $(10$ $\mathrm{ng}, 100 \mathrm{ng}$, and $1 \mu \mathrm{g}$ ) was amplified in parallel. A total of $20 \%-$ $50 \%$ of the products was separated by polyacrylamide gel electrophoresis and visualized by ethidium bromide staining. Band inten sity was determined by Chelimager software (AlphaInnotech).

\section{Construction of yeast intergenic microarrays}

Yeast microarrays of intergenic regions were prepared as described (Horak and Snyder 2002). Each intergenic region was printed in duplicate.

\section{Probe labeling and hybridization}

Labeling of chromatin-immunoprecipitated DNA involved three amplification steps. The first step employed a random octamer with a fixed sequence linker (5'-GTTTCCCAGTCAC GATCNNNNNNNN-3') and two cycles of T7 Sequenase (USB) polymerization. The thermal cycling conditions were as follows: $2 \mathrm{~min}$ at $94^{\circ} \mathrm{C}, 2 \mathrm{~min}$ at $8^{\circ} \mathrm{C}$, ramped for $8 \mathrm{~min}$ to $37^{\circ} \mathrm{C}$ and $8 \mathrm{~min}$ at $37^{\circ} \mathrm{C}$. This reaction mix was diluted in $1 \times \mathrm{TE}$ and purified by QIAGEN PCR purification system. All of the products were amplified by PCR using the fixed sequence primer (5'-GTTTCCCAGTCACGATC-3') and 2× QIAGEN Taq Mastermix in a $100-\mu \mathrm{L}$ volume. The thermal cycling conditions 
were as follows: $15-25$ cycles of $30 \mathrm{sec}$ at $92^{\circ} \mathrm{C}, 30 \mathrm{sec}$ at $40^{\circ} \mathrm{C}$, $30 \mathrm{sec}$ at $50^{\circ} \mathrm{C}$, and $1 \mathrm{~min}$ at $72^{\circ} \mathrm{C}$. Subsequently, $50 \%$ of the purified products were used for the amplification and labeling step. The primer and themal cycling conditions were the same as above, except that 2 nmole of either fluorscein-dCTP or biotin-dCTP (Perkin Elmer) were added along with unconjugated dCTP $(0.025 \mathrm{mM})$ and the remaining deoxy-nucleotides $(0.1$ $\mathrm{mM})$. Products were purified with a QIAGEN Minelute kit and the purified probe was combined with hybridization buffer $(5 \times$ SSC, $25 \%$ formamide, $0.1 \%$ SDS), boiled for $5 \mathrm{~min}$, and applied to a prehybridized yeast intergenic microarray. Microarrays were prehybridized with $5 \times$ SSC, $25 \%$ formamide, $0.1 \%$ SDS, and $1 \%$ BSA (bovine serum albumin) for $45 \mathrm{~min}$ at $42^{\circ} \mathrm{C}$. Slides were hybridized for $16 \mathrm{~h}$ at $42^{\circ} \mathrm{C}$ and washed and prepared according to instructions in the Micromax TSA labeling and detection kit (Perkin Elmer).

\section{Data analysis}

Microarrays were scanned with an Axon 4000A scanner and images were analyzed with Genepix Pro3.0 software. Spots with aberrant morphology or those with intensities below the threshold of detection were discarded. The raw data output from Genepix was processed as follow. (1) Data from a single microarray experiments was normalized to yield a $\mathrm{Cy} 5 / \mathrm{Cy} 3$ ratio of 1 for spots with no binding enrichment, using the following equation:

$$
\log (\mathrm{R} / \mathrm{G})=\log (\mathrm{R} / \mathrm{G})-\operatorname{ci}(\mathrm{I}, \mathrm{L})
$$

where $\mathrm{R}$ and $\mathrm{G}$ are the $\mathrm{Cy} 5$ and $\mathrm{Cy} 3$ intensities, respectively, and $\mathrm{c}$ is the scaling factor. The constant majority method was used to determine the scaling factors (Goryachev et al. 2001); as the $\mathrm{Cy} 5 / \mathrm{Cy} 3$ ratio is dependent on the intensity (I) and the array location of the spot $(\mathrm{L})$, a separate scaling factor was calculated for each spot $(i=1, \ldots, N$, where $N$ is the total number of spots) to account for these effects (Yang et al. 2002). (2) Replicate experiments were normalized to one another to scale the ratio spreads to a common range. For each experiment, a bootstrapped variance was calculated and the distributions were scaled such that they had equal variances. (3) Spot pairs (intergenic regions printed in duplicate) were excluded from further analysis if the variation between them was $>3$ standard deviations of the error distribution of the data points. (4) The ratio for each intergenic region was obtained by calculating the mean Cy5 and Cy3 intensities of spot pairs within each slide. The final sample ratio was calculated as the mean Cy5 and Cy3 value across replicate experiments. (5) Intergenic regions were identified as enriched target regions if the relative Cy 5 and Cy 3 intensities were at least 3.89 standard deviations $(\mathrm{p}<0.0001)$ beyond the distribution of the noise intensities (Fig. 3). The noise distribution was calculated from the data points with Cy3 > Cy5 intensities (i.e., below the diagonal). As no enrichment is expected for Cy3 in these experiments, any deviation in intensities from equal Cy5 and Cy3 intensities can be considered as experimental error. The cut-off $\mathrm{p}$ value was chosen to be sufficiently low as to give few expected false positives given the number of intergenic regions.

\section{Acknowledgments}

Thanks to Rebecca Goetsch, Ghia Euskirchen, and John Rinn for their assistance in constructing the yeast microarrays. The critical comments of Anthony Borneman, Nelson Lopez Ghil Jona, Scott Bidlingmaier, and Daniel Gelperin in the reading of this manuscript are also much appreciated. We thank Paul Bertone for his assistance in designing figures and the Web page. Work in the Snyder and Gerstein laboratories is supported by NIH grants CA77808 and HG02357. N.M.L. is sponsored by the
Anna Fuller Fund and C.E.H. is supported by a Howard Hughes Predoctoral Fellowship.

The publication costs of this article were defrayed in part by payment of page charges. This article must therefore be hereby marked "advertisement" in accordance with 18 USC section 1734 solely to indicate this fact.

\section{References}

Amon, A., Tyers, M., Futcher, B., and Nasmyth, K. 1993. Mechanisms that help the yeast cell cycle clock tick: G2 cyclins transcriptionally activate G2 cyclins and repress G1 cyclins. Cell 74: 993-1007.

Andrews, B.J. and Herskowitz, I. 1989a. Identification of a DNA binding factor involved in cell-cycle control of the yeast $\mathrm{HO}$ gene. Cell 57: 21-29.

. $1989 \mathrm{~b}$. The yeast SWI4 protein contains a motif present in developmental regulators and is part of a complex involved in cell cycle-dependent transcription. Nature 342: 830-833.

Banuett, F. 1998. Signalling in the yeasts: An informational cascade with links to the filamentous fungi. Microbiol. Mol. Biol. Rev. 62: 249-274.

Barral, Y., Jentsch, S., and Mann, C. 1995. G1 cyclin turnover and nutrient uptake are controlled by a common pathway in yeast. Genes \& Dev. 9: 399-409.

Breeden, L. and Mikesell, G.E. 1991. Cell cycle-specific expression of the SWI4 transcription factor is required for the cell cycle regulation of HO transcription. Genes \& Dev. 5: 1183-1190.

Breitkreutz, A., Boucher, L., and Tyers, M. 2001. MAPK specificity in the yeast pheromone response independent of transcriptional activation. Curr. Biol. 11: 1266-1271.

Cho, R., Campbell, M., Winzeler, E., Steinmetz, L., Conway, A., Wodicka, L., Wolfsberg, T., Gabrielian, A., and Davis, R. 1998. A genome-wide transcriptional analysis of the mitotic cell cycle. Mol. Cell 2: 65-73.

Cross, F.R., Hoek, M., McKinney, J.D., and Tinkelenberg, A.H. 1994. Role of Swi4 in cell cycle regulation of CLN2 expression. Mol. Cell. Biol. 14: 4779-4787.

Deshaies, R., Chau, V., and Kirschner, M. 1995. Ubiquitination of the G1 cyclin $C \ln 2 \mathrm{p}$ by a Cdc34p-dependent pathway. EMBO I. 14: 303-312.

Dirick, L., Moll, T., Auer, H., and Nasmyth, K. 1992. A central role for SWI6 in modulating cell cycle Start-specific transcription in yeast. Nature 357: 508-513.

Dirick, L., Bohm, T., and Nasmyth, K. 1995. Roles and regulation of Cln-Cdc28 kinases at the START of the cell cycle of Saccharomyces cerevisiae. EMBO J. 14: 4803-4813.

Freedman, T., Porter, A., and Haarer, B. 2000. Mutational and hyperexpression-induced disruption of bipolar budding in yeast. Microbiology 146: 2833-2843.

Gasch, A., Huang, M., Metzner, S., Botstein, D., Elledge, S., and Brown, P. 2001. Genomic expression responses to DNAdamaging agents and the regulatory role of yeast ATR homolog Meclp. Mol. Biol. Cell 12: 2987-3003.

Goryachev, A., MacGregor, P., and Edwards, A. 2001. Unfolding of microarray data. J. Comput. Biol. 8: 443-461.

Harrington, L.A. and Andrews, B.J. 1996. Binding to the yeast Swi4,6-dependent cell cycle box, CACGAAA, is cell cycle regulated in vivo. Nucleic Acids Res. 24: 558-565.

Horak, C.E. and Snyder, M. 2002. ChIp-chip: A genomic approach for identifying transcription factor binding sites. Methods Enzymol. 350: 469-483.

Igual, J.C., Johnson, A.L., and Johnston, L.H. 1996. Coordinated regulation of gene expression by the cell cycle transcription factor SWI4 and the protein kinase C MAP kinase pathway 
for yeast cell integrity. EMBO J. 15: 5001-5013.

Ito, H., Fukada, Y., Murata, K., and Kimura, A. 1983. Transformation of intact yeast cells with alkali cations. J. Bacteriol. 153: $163-168$.

Iyer, V.R., Horak, C.E., Scafe, C.S., Botstein, D., Snyder, M., and Brown, P.O. 2001. Genomic binding sites of the yeast cellcycle transcription factors SBF and MBF. Nature 409: 533-538.

Jelinsky, S., Estep, P., Church, G., and Samson, L. 2000. Regulatory networks revealed by transcriptional profiling of damaged Saccharomyces cerevisiae cells: Rpn4 links base excision repair with proteasomes. Mol. Cell. Biol. 20: 8157-8167.

Kaufmann, E. 1993. In vitro binding to the leucine tRNA gene identifies a novel yeast homeobox gene. Chromosoma 102: 174-179.

Koch, C., Moll, T., Neuberg, M., Ahorn, H., and Nasmyth, K. 1993. A role for the transcription factors Mbp1 and Swi4 in progression from G1 to S phase. Science 261: 1551-1557.

Koranda, M., Schleiffer, A., Endler, L., and Ammerer. G. 2000. Forkhead-like transcription factors recruit Ndd1 to the chromatin of G2/M-specific promoters. Nature 406: 94-98.

Kumar, R., Reynolds, D., Shevchenko, A., Goldstone, S., and Dalton, S. 2000. Forkhead transcription factors, Fkhlp and Fkh2p, collaborate with Mcmlp to control transcription required for M-phase. Curr. Biol. 10: 896-906.

Kumar, A., Agarwal, S., Heyman, J., Matson, S., Heidtman, M., Piccirillo, S., Umansky, L., Drawid, A., Jansen, R., Liu, Y., et al. 2002. Subcellular localization of the yeast proteome. Genes \& Dev. 16: 707-719.

Kunoh, T., Kaneko, Y., and Harashima, S. 2000. YHP1 encodes a new homeoprotein that binds to the IME1 promoter in Saccharomyces cerevisiae. Yeast 16: 439-449.

Leza, M. and Elion, E. 1999. POG1, a novel yeast gene, promotes recovery from pheromone arrest via the G1 cyclin CLN2. Genetics 151: 531-543.

Lowndes, N.F., Johnson, A.L., Breeden, L., and Johnston, L.H. 1992. SWI6 protein is required for transcription of the periodically expressed DNA synthesis genes in budding yeast. Nature 357: 505-508.

Madden, K., Sheu, Y.-J., Baetz, K., Andrews, B., and Snyder, M. 1997. SBF cell cycle regulator as a target of the yeast PKCMAP kinase pathway. Science 275: 1781-1784.

Moll, T., Dirick, L., Auer, H., Bonkovsky, J., and Nasmyth, K. 1992. SWI6 is a regulatory subunit of two different cell cycle START-dependent transcription factors in Saccharomyces cerevisiae. J. Cell Sci. Suppl. 16: 87-96.

Nasmyth, K. and Dirick, L. 1991. The role of SWI4 and SWI6 in the activity of G1 cyclins in yeast. Cell 66: 995-1013.

Nishi, K., Park, C., Pepper, A., Eichinger, G., Innis, M., and Holland, M. 1995. The GCR1 requirement for yeast glycolytic gene expression is suppressed by dominant mutations in the SGC1 gene, which encodes a novel basic-helix-loophelix protein. Mol. Cell. Biol. 15: 2646-2653.

Ogas, J., Andrews, B.J., and Herskowitz, I. 1991. Transcriptional activation of CLN1,CLN2, and a putative new G1 cyclin (HCS26) by SWI4, a positive regulator of G1-specific transcription. Cell 66: 1015-1026.

Pan, X. and Heitman, J. 2000. Sok2 regulates yeast pseudohyphal differentiation via a transcription factor cascade that regulates cell-cell adhesion. Mol. Cell. Biol. 22: 8364-8372.

Pic, A., Lim, F., Ross, S., Veal, E., Johnson, A.L., Sultan, M., West, A., Johnston, L.H., Sharrocks, A., and Morgan, B. 2000. The forkhead protein Fkh2 is a component of the yeast cell cycle transcription factor SFF. EMBO J. 19: 3750-3761.

Pramila, T., Miles, S., GuhaThakurta, D., Jemiolo, D., and Breeden, L.L. 2002. Conserved homeodomain proteins interact with MADS box protein Mcm1 to restrict ECB-dependent tran- scription to the M/G1 phase of the cell cycle. Genes \& Dev. 16: (this issue).

Primig, M., Sockanathan, S., Auer, H., and Nasmyth, K. 1992. Anatomy of a transcription factor important for the Start of the cell cycle in Saccharomyces cerevisiae. Nature 358: 593-597.

Rabitsch, K., Toth, A., Galova, M., Schleiffer, A., Schaffner, G., Aigner, E., Rupp, C., Penkner, A., Moreno-Borchart, A., Primig, M., et al. 2001. A screen for genes required for meiosis and spore formation based on whole-genome expression. Curr. Biol. 11: 1001-1009.

Ross-MacDonald, P., Sheehan, A., Roeder, G., and Snyder, M. 1997. A multi-purpose transposon system for analyzing protein production, localization, and function in Saccharomyces cerevisiae. Proc. Natl. Acad. Sci. 94: 190-194.

Sambrook, J., Fritsch, E., and Maniatis, T. 1989. Molecular cloning: A laboratory manual. Cold Spring Harbor Laboratory Press, Cold Spring Harbor, NY.

Sato, T., Lopez, M., Sugioka, S., Jigami, Y., Baker, H., and Uemura, H. 1999. The E-box DNA binding protein Sgclp suppresses the $g c r 2$ mutation, which is involved in transcriptional activation of glycolytic gene in Saccharomyces cerevisiae. FEBS Letts. 463: 307-311.

Schneider, B.L., Seufert, W., Steiner, B., Yang, Q.H., and Futcher, A.B. 1995. Use of polymerase chain reaction epitope tagging for protein tagging in Saccharomyces cerevisiae. Yeast 11: 1265-1274.

Schwob, E., Bohm, T., Mendenhall, M.D., and Nasmyth, K. 1994. The B-type cyclin kinase inhibitor $\mathrm{p} 40^{\mathrm{SIC} 1}$ controls the G1 to $S$ transition in S. cerevisiae. Cell 79: 233-244.

Simon, I., Barnett, J., Hannett, N., Harbison, C.T., Rinaldi, N.J., Zeitlinger, J., Gifford, D.K., Jaakkola, T.S., and Young, R.A. 2001. Serial regulation of transcriptional regulators in the yeast cell cycle. Cell 106: 697-708.

Spellman, P., Sherlock, G., Zhang, M., Iyer, V., Anders, K., Eisen, M., Brown, P., Botstein, D., and Futcher, B. 1998. Comprehensive identification of cell cycle-regulated genes of the yeast Saccharomyces cerevisiae by microarray hybridization. Mol. Biol. Cell 9: 3273-3297.

Verma, R., Smiley, J., Andrews, B., and Campbell, J.L. 1992. Regulation of the yeast DNA replication genes through the MluI cell cycle box is dependent on SWI6. Proc. Nat1. Acad. Sci. 89: 9479-9483.

Verma, R., Annan, R., Huddleston, M., Carr, S., Reynard, G., and Deshaies, R. 1997. Phosphorylation of Siclp by G1 Cdk required for its degradation and entry into $\mathrm{S}$ phase. Science 278: 455-460.

Willems, A., Lanker, S., Patton, E., Craig, K., Nason, T., Mathias, N., Kobayashi, R., Wittenberg, C., and Tyers, M. 1996. Cdc53 targets phosphorylated G1 cyclins for degradation by the ubiquitin proteolytic pathway. Cell 86: 453-463.

Yang, Y., Dudoit, S., Luu, P., Lin, D., Peng, V., Ngai, J., and Speed, T. 2002. Normalization for cDNA microarray data: a robust composite method addressing single and multiple slide systematic variation. Nucleic Acids Res. 30: e15.

Zhu, G. and Davis, T. 1998. The fork head transcription factor Hcmlp participates in the regulation of SPC110, which encodes the calmodulin-binding protein in the yeast spindle pole body. Biochim. Biophys. Acta 1448: 236-244.

Zhu, G., Muller, E., Amacher, S., Northrop, J., and Davis, T. 1993. A dosage-dependent suppressor of a temperature-sensitive calmodulin mutant encodes a protein related to the fork head family of DNA-binding proteins. Mol. Cell. Biol. 13: $1779-1787$.

Zhu, G., Spellman, P., Volpe, T., Brown, P., Botstein, D., Davis, T., and Futcher, B. 2000. Two yeast forkhead genes regulate the cell cycle and pseudohyphal growth. Nature 406: 90-94. 


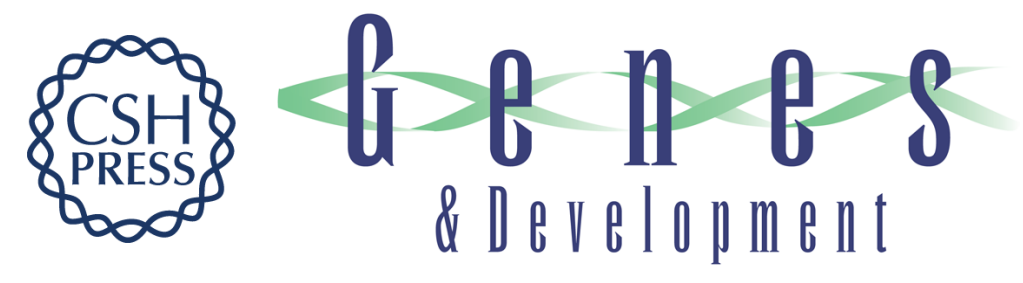

\section{Complex transcriptional circuitry at the G1/S transition in Saccharomyces cerevisiae}

Christine E. Horak, Nicholas M. Luscombe, Jiang Qian, et al.

Genes Dev. 2002, 16:

Access the most recent version at doi:10.1101/gad.1039602

Supplemental http://genesdev.cshlp.org/content/suppl/2002/12/05/16.23.3017.DC1
Material

References This article cites 49 articles, 18 of which can be accessed free at:

http://genesdev.cshlp.org/content/16/23/3017.full.html\#ref-list-1

License

Email Alerting Receive free email alerts when new articles cite this article - sign up in the box at the top

Service right corner of the article or click here.

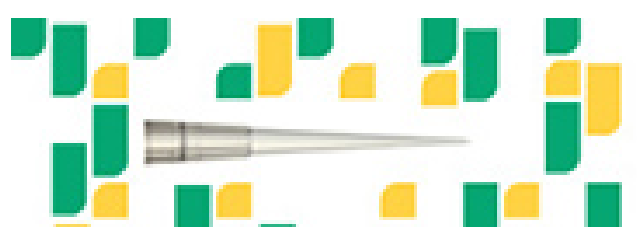

Focused on your science. 